\title{
Reconceptualizing Ego Depletion as Transient Cognitive Fatigue
}

\author{
Patrick J. Hurley \\ D’Amore-McKim School of Business, Northeastern University
}

\begin{abstract}
Author Note
Patrick J. Hurley (D) https://orcid.org/0000-0003-4117-187X

I have no known conflicts of interest to disclose.

Correspondence concerning this article should be addressed to Patrick J. Hurley, Northeastern

University, 360 Huntington Avenue, Boston, MA 02115. Email: p.hurley@northeastern.edu
\end{abstract}




\begin{abstract}
Ego depletion is embroiled in a crisis that has cast doubts over the legitimacy of the phenomenon itself and its theoretical explanation. I first summarize and analyze the strength model of selfcontrol as cohesive theoretical explanations of the phenomenon and highlight the difficulties it creates for depletion researchers. I conclude that the strength model is not the best theoretical explanation for the depletion phenomenon. Rather, I propose reconceptualizing the ego depletion effect as transient cognitive fatigue (TCF). To support this theoretical shift, I highlight how both the classic and disparate findings in the depletion literature cleanly map into the literature on cognitive fatigue, and how considering depletion to be TCF accommodates existing theoretical alternatives to the strength model.
\end{abstract}

Keywords: ego depletion, motivation, transient cognitive fatigue, mental fatigue 


\section{Reconceptualizing Ego Depletion as Transient Cognitive Fatigue}

Ego depletion features prominently in psychology's replication crisis due to meta-analyses (e.g., Carter et al. 2015) and registered replication reports (e.g., Hagger et al. 2016; Vohs et al. in press) that have cast doubt that depletion is even a legitimate phenomenon, despite several hundreds of published studies supporting its existence (Cunningham \& Baumeister, 2016; Baumeister, 2019). Some scholars have even cast doubt that depletion will be reliably detected as a significant effect after 2020 (e.g., Vadillo, 2019). The main threats to ego depletion entail two questions: first, does depletion exist as a valid psychological phenomenon; and second, do the existing theoretical accounts that purport to explain the phenomenon succeed in doing so?

In this paper, I primarily address the theory underlying ego depletion, which I argue does not accurately capture the phenomenon. I discuss some issues regarding the phenomenon itself, as do others (e.g., Friese et al. 2019 for an in-depth analysis) and conclude that the ego depletion phenomenon has not been invalidated, but is likely overstated in the prior literature. However, based upon shortcomings of existing theory at explaining the phenomenon, I suggest reconceptualizing ego depletion as transient cognitive fatigue. Contrary to popular belief and despite over 100 years of research, the literature on cognitive fatigue has not reached a comprehensive theory (Hockey, 2011). I highlight numerous empirical and theoretical similarities between the depletion and cognitive fatigue literatures and propose that it is more appropriate to consider the depletion phenomenon to be transient cognitive fatigue (TCF). This reconceptualization of the depletion phenomenon at a theoretical level is intended to guide continued study of this phenomenon and to contribute to a more holistic understanding of cognitive fatigue. It is also important to integrate the concepts of depletion and TCF, because if concepts are 
fragmented in the literature it can slow the dissemination of research findings and lead to lesswell-informed research (Pattyn et al., 2018).

Ego depletion research is grounded in the concept of self-control. ${ }^{1}$ Self-control has been defined in prior research as numerous inhibitory and initiatory processes through which individuals alter their own thoughts, emotions, impulses, performances, and behaviors, based upon standards and/or to guide behavior toward desired end states or goals (Baumeister \& Vohs, 2016a; Inzlicht et al. 2020). The depletion literature has largely relied upon the strength model of self-control (hereafter also "strength model"), which posits that self-control behavior relies upon a finite and expendable cognitive resource. Exercising self-control resource depletes this resource and causes a state of diminished self-control resources termed "ego depletion" (Baumeister and Vohs, 2016 p. 70). Ego depletion was originally posited as individuals' inability to effectively exercise selfcontrol when depleted (e.g., Baumeister et al., 1998; Muraven et al., 1998; Baumeister, 2002; Baumeister et al., 2007), although researchers have increasingly acknowledged that it is an unwillingness, rather than an inability to do so (Baumeister \& Vohs, 2016a).

\section{Crisis of Phenomenon: Is Ego Depletion Real?}

\section{Meta-Analyses and Conflicting Results}

Despite hundreds of published studies both supporting and extending depletion in various ways (Cunningham \& Baumeister, 2016), and supportive meta-analyses (e.g., Hagger et al. 2010), many researchers have begun to doubt the validity of depletion as a phenomenon. Given that a number of papers address the issue of whether depletion exists as a phenomenon, subsequent to the replicability crisis (e.g., see Friese et al., 2019; Inzlicht \& Friese, 2019; Hurley 2021 for

\footnotetext{
${ }^{1}$ While the ego depletion literature uses self-control and self-regulation somewhat interchangeably, these terms likely refer to distinct processes (Milyavskaya et al. 2019a). Self-regulation is the broader term that subsumes self-control (Inzlicht et al., 2020); as a result, I conservatively use self-control in the current paper.
} 
reviews), I only briefly discuss the challenges to depletion as a phenomenon, which primarily arise from two sources: meta-analyses and registered replication reports.

Carter \& McCullough (2014) re-analyzed the data in the Hagger et al. (2010) meta-analysis and found evidence of significant publication bias; however, they report statistically significant and moderate-to-large effect sizes for depletion using the trim-and-fill method for correcting publication bias ( $g=0.48$ to 0.50 ), but do not find a significant effect using PET-PEESE biascorrection. Carter et al. (2015) conducted an updated meta-analysis to alleviate publication bias by including both published and unpublished studies. ${ }^{2}$ In their broadest analysis, Carter et al. (2015 p. 806) report a medium effect size of depletion $(g=0.43)$, and significant depletion effects for six of their eight task-based subgroups using the trim-and-fill bias-correction method, with a significant but small combined effect size $(g=0.24)$. Using PET-PEESE correction in each of their eight subgroups, Carter et al. (2015) fail to find a true effect of depletion that is significantly different from zero. It is seemingly based upon this analysis that Carter et al. (2015 p. 796) conclude that they "find very little evidence that the ego depletion effect is real phenomenon." However, the vast majority of these authors' analyses seem to suggest that depletion is a real phenomenon.

Several additional meta-analyses supportive of the depletion effect have subsequently been published. Dang (2018) reports a small-to-medium effect size across all studies $(g=0.38)$ and a small effect size $(g=0.24)$ when using trim-and-fill bias correction. In an analysis of only low heterogeneity tasks, Dang (2018) finds a small-to-medium effect $(g=0.42)$ and a large effect size using PET-PEESE bias correction $(g=0.56)$. Blázquez et al. (2017) re-analyze the results from

\footnotetext{
${ }^{2}$ Of 620 experiments identified by Carter et al. (2015 p. 799), only 116 were included in their broadest metaanalyses and, of these 116 studies, only 28 of the 198 published experiments from the Hagger et al. (2010) sample were included.
} 
Hagger et al. (2010) and Carter et al. (2015) using the p-uniform test and find medium-to-large effect sizes $(d=0.64$ to 0.66$)$ for both datasets. ${ }^{3}$ Table 1 summarizes the findings of the broadest samples within each meta-analysis and largely indicates that each meta-analysis finds a significant depletion effect with the notable exceptions of models employing PET-PEESE bias correction.

Table 1: Summary of Ego Depletion Meta-Analyses

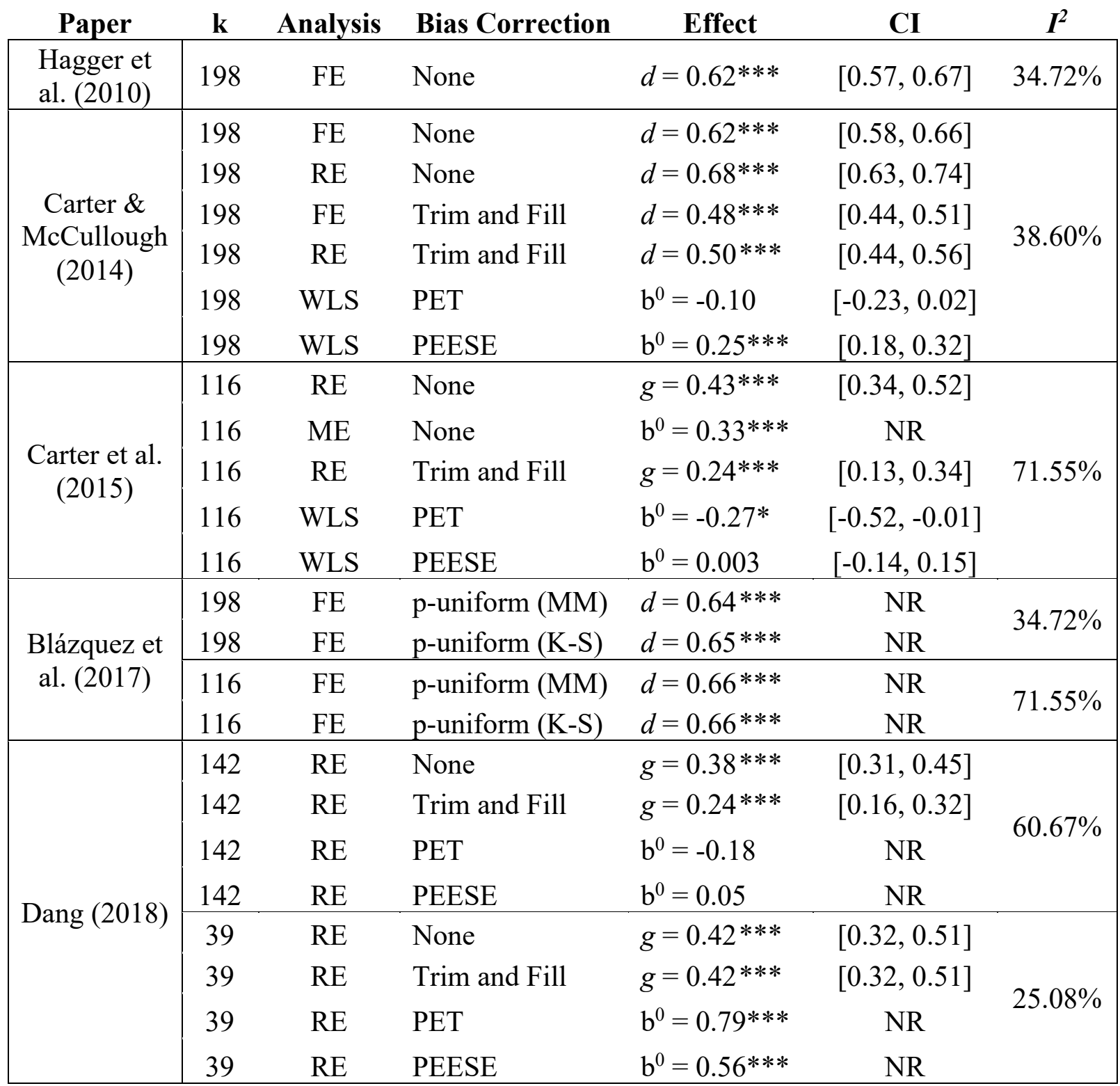

\footnotetext{
${ }^{3}$ The p-uniform method corrects publication bias but performs poorly with high average p-values (i.e., $0.025<\mathrm{p}<$ 0.050 ) or if heterogeneity is high (Blázquez et al., 2017). However, average p-values for the Hagger et al. (2010) and Carter et al. (2015) datasets were 0.011 and 0.012 (medians both $=0.007$ ), respectively, and only Carter et al.'s (2015) data exhibiting heterogeneity above the reasonable threshold.
} 
This table presents the results of several meta-analyses of the ego depletion effect. Column ' $\mathrm{k}$ ' indicates the number of independent tests of depletion included in the meta-analysis. The 'Analysis' column classifies analyses as fixed effects (FE), random effects (RE), mixed effects (ME), or weighted least squares (WLS). In the 'Bias Correction' column, MM refers to the method-of-the-moments test and K-S refers to the minimal Kolmogorov-Smirnov test. Column ' ${ }^{21}$ refers to heterogeneity in effect size. NR indicates that confidence intervals were not reported within a specific study. It is important to note that Dang's (2018) sample size of 39 reflects studies using three specific depleting tasks with low heterogeneity (attention essay, emotion video, and Stroop task); the low heterogeneity of this subsample allowed PET-PEESE bias correction to be used effectively. ***, and $* * *$ correspond to significance at the $0.05,0.01$, and 0.001 levels, respectively.

Of significant concern for depletion meta-analyses is a body of literature that has identified significant concerns with meta-analytic methodologies for bias correction. Psychological data often violate the assumptions of the trim-and-fill method (Duval \& Tweedie, 2000), and researchers argue the trim-and-fill method for bias correction over-corrects for non-existent bias and fails with high heterogeneity (Friese et al., 2019; Carter et al., 2019 p. 121). With respect to PET-PEESE analyses, researchers recommend avoiding these analyses due to general unreliability, over- and under-corrections, and tendency to underestimate effect sizes, especially under conditions typical of psychological data (e.g., heterogeneity in effect sizes and publication bias) (Carter et al., 2019 pp. 123-124). The creators of this method (Stanley \& Doucouliagos, 2014; Stanley, 2017) also highlight that PET-PEESE methods exhibit "unacceptable performance" in areas with few (e.g., < 20) studies, small sample effects, and high heterogeneity of results, which are all common to ego depletion research (Carter et al., 2019 p. 124). For example, there were less than 20 studies in seven of eight task-based groupings (the other had 21) in which Carter et al. (2015) applied PET-PEESE to arrive at their conclusion of little to no effect of depletion. Finally, the p-uniform method (Blázquez et al., 2017) assumes homogeneous effect sizes, that nonstatistically significant studies are uninformative, and that significant studies have equal likelihood of publication regardless of the level of statistical significance (Friese et al., 2019), and exhibits upward bias on effect sizes when its assumptions are violated (Carter et al., 2019). 
In summary, it seems that the various meta-analyses that are both supportive (Hagger et al., 2010; Dang, 2018; Blázquez et al., 2017) and not supportive (Carter \& McCullough, 2014; Carter et al., 2015) of depletion being a real phenomenon suffer from potential bias resulting from methodological issues (Cunningham \& Baumeister, 2016). Despite these issues, nearly all of the broadest analyses in these meta-analyses indicate that depletion is a real phenomenon. As a result, these meta-analyses do not seem to provide sufficient evidence to conclude that ego depletion is not a real phenomenon.

\section{Registered Replication Reports}

Two large-scale registered replication reports (RRRs) have emerged in the past five years: Hagger et al. (2016) and Vohs et al. (in press). Hagger et al. (2016) found a tiny effect size of ego depletion (Cohen's $d=0.04$ ) with a 95 percent CI that included zero. These findings led the authors to conclude "if there is any effect [of depletion], it is close to zero" (Hagger et al. 2016 p. 558). Despite the statistical power of the Hagger et al. (2016) study, researchers have questioned whether the authors successfully manipulated depletion (Drummond \& Philipp, 2017; Baumeister \& Vohs, 2016b; Dang, 2016), and whether motivational differences may have produced the results (Sripada et al. 2016). ${ }^{4}$

Vohs et al. (in press) conducted a large-scale "paradigmatic replication" of the depletion effect. Confirmatory tests yielded a non-significant result $(\mathrm{d}=0.06)$ with Bayesian meta-analyses indicating the data were four times more likely to obtain under the null hypothesis than the alternative hypothesis. In exploratory analyses that relaxed strict exclusion criteria, the authors

\footnotetext{
${ }^{4}$ Specifically, Sripada et al. (2016) expressed concern at the high exclusion rate of participants due to low accuracy (26 percent on average versus 13 percent in Sripada et al. 2014). Specifically, 958 of 3,099 (30.9 percent of) original participants were excluded, of which 808 (83.4 percent) were due to low accuracy. The accuracy-related exclusions fell disproportionately in the depletion condition (462 of 1,550, 29.8 percent) versus the control condition (346 of $1,549,22.3$ percent $)\left(t_{3,097}=4.75, \mathrm{p}<0.001\right)$. When including these participants, Hagger et al. (2016) find a small but statistically significant depletion effect $(g=0.08)$.
} 
found a statistically significant, but small effect $(d=0.08)$, with Bayesian meta-analyses indicating that the data were equally likely under the null and alternative hypotheses. Further, of interest to my theoretical arguments, moderator tests indicated that the depletion effect was larger for participants reporting higher levels of fatigue.

While these RRRs findings of a null effect do represent a significant threat to the existence of depletion as a phenomenon, they should be viewed in context. As Friese et al. (2019 p. 112) note, a few particular IV-DV combinations are necessarily limited in their ability to validate or invalidate depletion as a phenomenon, and "[i]t appears premature and logically unjustified to dismiss the phenomenon and the complete existing ego depletion literature based on...one specific study, even a statistically powerful one".

\section{Conclusions about the Threats to Ego Depletion as a Phenomenon}

In this section I have briefly discussed the main threats to the depletion phenomenon, which include contradictory meta-analyses and two high-powered RRRs that found a null effect for depletion. However, the large number of studies finding evidence of depletion provide support that depletion is a real phenomenon, although they do not necessarily indicate that the strength model is the correct theoretical account for depletion. Even considering the influence of publication biases, p-hacking, and other questionable research practices (see Friese et al. 2019 for a detailed discussion), to observe so many published studies on a topic for which no true effect exists seemingly implies either capitalizing on chance or academic fraud on a massive scale, neither of which seems plausible. ${ }^{5}$

\footnotetext{
${ }^{5}$ For studies to have capitalized on chance for a non-existent phenomenon implies that results should systematically vary around a mean of zero, which would necessarily produce negative results (i.e., depletion improves performance, or a "reverse effect") that are novel and counterintuitive relative to theory, and thus highly publishable (Friese et al., 2019; Baumeister, 2019; Hagger \& Chatzisarantis, 2014). Yet, only a handful of studies report reverse effects (e.g., Converse \& DeShon, 2009; Job et al., 2010; DeWall et al., 2011; Carter \& McCullough, 2013; Tuk et al., 2015; Van Reet, 2015; Savani \& Job, 2017), and many of these studies predict these results based upon other theories, meaning they are not theoretically unexpected effects, as would occur if depletion had a true null effect.
} 
While the threats to ego depletion presented in this section are significant and challenging, none of them provides conclusive evidence that ego depletion does not exist as a phenomenon. As a result, it seems premature to dismiss the phenomenon altogether (Friese et al., 2019). Indeed, one might view the current crisis in ego depletion as normal science operating as it is intended. In normal science, findings accumulate through tests of theory, and this process generates "anomalies" (i.e., deviations from theory-driven expectations) that accumulate until they reach a critical mass (Kuhn, 2012). At this point, theories are revised so as to accommodate the anomalies or are discarded and replaced if a competing theory emerges that can better account for the phenomenon. Ego depletion research has certainly uncovered anomalies in the form of the RRRs discussed above and mixed findings in recent studies. Efforts to provide theoretical updates to the strength model (Baumeister \& Vohs, 2016a) and alternative theories to explain the depletion phenomenon indicate that this is, at a high level, precisely how scientific research is supposed to work. Nowhere in this view of scientific progress is it considered a best option to entirely dismiss hundreds of studies and abandon theoretical explanation for a phenomenon that much of prior research supports as valid. ${ }^{6}$ Yet, as Inzlicht and Friese (2019) note, this is what many researchers seem ready to do with depletion.

In my view, the accumulating mixed results are not to be viewed so much as evidence that the phenomenon does not exist, but that it does not exist as specified by the theory, due to the overly broad and vague nature of the strength model. ${ }^{7}$ In the context of normal science, the accumulation of anomalies suggests that the theory may not be appropriately specified, which

\footnotetext{
${ }^{6}$ Kuhn (2012 p. 77) notes "[t]hough they may...lose faith and...consider alternatives, they do not renounce the paradigm that has led them into crisis. They do not, that is, treat anomalies as counterinstances."

${ }^{7}$ Kuhn (2012 p. 65) specifically notes "Anomal[ies] appear only against the background provided by the paradigm. The more...far reaching that paradigm is, the more sensitive an indicator it provides of anomaly and hence of an occasion for paradigm change."
} 
serves as the impetus for my suggested theoretical re-specification of ego depletion as transient cognitive fatigue. This process seems to be what Kuhn envisioned when he detailed the accumulation of anomalies compared to theoretical predictions, and the process by which an alternative theory is formulated to replace the incumbent theory.

\section{Crisis of Theory: What is Ego Depletion?}

\section{Issues with and Updates to the Strength Model}

While it seems that ego depletion does exist as a real (albeit likely overstated) phenomenon, it also seems that the strength model is too vaguely specified to be certain as to the exact causal mechanisms underlying the phenomenon. The strength model defines depletion as a behavioral phenomenon (reduced self-control performance subsequent to self-control exertion), rather than by specifying precise causal mechanisms (Friese et al., 2019). The strength model specifies that the causal mechanism in the depletion effect is self-control resources, which are not readily observable or measurable, leavign depletion to be inferred from impaired performance on the dependent variable task. The inability to observe or measure the underlying causal mechanism in energy or resource models has led researchers to criticize these models as being unfalsifiable (Hockey, 2013; Inzlicht \& Berkman, 2015; Navon, 1984).

This resource-based theoretical specification has led to overly broad definitions of selfcontrol and circular logic in justifying task choice (Lurquin \& Miyake, 2017), while also making it difficult for researchers to know if they have successfully manipulated depletion. As a result, the depletion literature features loosely-related tasks (e.g., taking standardized tests, Schmeichel et al. 2003; balancing on one leg, Tyler \& Burns 2008) that purport to capture self-control. Vague theoretical specification has also created considerable confusion regarding what tasks reliably produce depletion, which is evident when different studies use the same task (e.g., 3-digit by 3- 
digit multiplication) as both a depleting manipulation (e.g., Stillman et al., 2009) and a control condition (e.g., Burkley, 2008).

To address criticisms and incorporate recent evidence, Baumeister \& Vohs (2016) update the strength model and provide a detailed review of competing theories before settling on adding to the strength model a controversial concept from exercise psychology: a central governor (Noakes, 1997; Evans et al., 2015). In this view, a vague “central governor” monitors the body's self-control exertion and seeks to conserve glucose if the body's current rate of consumption would eventually create untenably low glucose levels. Notwithstanding the fact that prior research does not find that self-control exertion consumes inordinate amounts of energy (e.g., Inzlicht \& Marcora, 2016), adding a central governor to the strength model exacerbates issues of falsifiability rather than resolves them (e.g., Inzlicht \& Marcora, 2016; Lurquin \& Miyake, 2017).

\section{Conclusions about the Threats to Ego Depletion Theory}

Based upon the preceding discussion I conclude that the strength model of self-control does not seem to be best equipped to explain the depletion phenomenon. In response to the issues surrounding the strength model as a theoretical explanation of the depletion phenomenon, researchers have set forth numerous competing theories to explain depletion. I review these alternative theories, all of which seemingly entail motivation as a key component, in a later section of the paper when comparing them to a view of depletion as transient cognitive fatigue.

Contrary arguments that depletion is not cognitive fatigue (e.g., Vohs et al., 2010), researchers have increasingly acknowledged that depletion is a form of cognitive fatigue (e.g., Baumeister et al., 2018; Baumeister, 2019; Hagger \& Chatzisarantis, 2016), and Inzlicht et al. (2014) posit that ego depletion and mental fatigue may refer to identical psychological constructs. Thus, it seems that integrating depletion and cognitive fatigue can yield significant insights 
through further study of this phenomenon. Indeed, alternatives to the strength model suggest commonalities between depletion and cognitive fatigue (e.g., Kurzban et al., 2013; Inzlicht et al., 2014; Inzlicht \& Berkman, 2015). In the next section, I draw extensive parallels between the depletion and cognitive fatigue literatures and later discuss how a motivation-centric reconceptualization of depletion as transient cognitive fatigue can subsume competing theoretical accounts of the depletion phenomenon.

\section{Ego Depletion and Transient Cognitive Fatigue}

Below I argue that the depletion phenomenon is best theoretically conceptualized as transient cognitive fatigue ("TCF"). This reconceptualization clarifies that tasks expected to cause TCF do so through cognitive effort demands and motivation and resolves the theoretical ambiguity inherent in the strength model. I examine the cognitive fatigue literature and highlight similarities between this literature and prior findings on depletion. In doing so, I demonstrate that many findings in the depletion literature map cleanly into a motivation-centric theory of TCF.

\section{Defining Cognitive Fatigue}

Cognitive fatigue (hereafter also "fatigue") is ubiquitous, has a pervasive impact on everyday life, and is nearly universally experienced at some point or another. Thus, the appeal of both fatigue and depletion seems largely driven by the commonality and relatability of the experience in everyday life. However, this ubiquity and widespread experience of fatigue has fostered an incorrect belief that fatigue itself and its consequences are well understood. The existing academic literature on fatigue does not support this belief, as fatigue remains poorly understood among both the scientific community as well as laypeople (Hockey, 2013; Ackerman, 2011). Fatigue is a complex state entailing changes in motivation, emotion, behavior, and information processing capabilities (van der Linden, 2011), and therefore requires further research 
to understand this complexity. I propose that considering depletion as TCF can help to further our understanding of fatigue and how it might affect individuals in specific ways.

Cognitive or mental fatigue is "a psychobiological state caused by prolonged periods of demanding cognitive activity and characterized by subjective feelings of 'tiredness' and 'lack of energy" (Marcora et al., 2009). Fatigue is a state of mental discomfort and an aversion to effortful mental activity that accumulates with continued effort on a task (Thorndike, 1900). It is therefore easiest to conceptualize fatigue by relying upon the universally recognized and understood subjective experience of feeling mentally tired (Hockey, 2013 p. 13). While it is typically assumed that cognitive fatigue results only from task performance exceeding 30 minutes (e.g., Van Cutsem et al., 2017), it is likely that cognitive fatigue is broader and occurs in situations other than prolonged exposure to high levels of cognitive activity (Hockey 2013).

It is also important to note that while many consider fatigue to represent simple interference with an individual's ability to effectively perform tasks, fatigue is not necessarily associated with a decrement in task performance because individuals can employ compensatory effort to maintain performance and goals, especially when motivated to do so (Locke \& Braver, 2008; Sarter et al., 2006; Hockey, 1997). This is an important contrast with ego depletion, as the dual-task paradigm is predicated upon observing a performance decrement as evidence of depletion. However, performance is just one aspect of goal regulation and need not occur concurrently with strong subjective feelings of fatigue (Hockey, 2013 p. 76).

OBSERVATION \#1: Short-term effort exertion is not necessarily followed by a performance decrement, which potentially explains the mixed results in depletion studies.

\section{Components of Cognitive Fatigue}

Because fatigue is a multi-causal phenomenon, it is first useful to specify and elaborate upon the executive functions that are closely related to fatigue: goal maintenance and monitoring; 
motivation; effort regulation; and attention regulation. ${ }^{8}$ First, goals represent the starting point for any meaningful behavior, and effort is (or is not) expended, monitored, and maintained in an attempt to achieve that outcome (Powers, 1973).

Second, a lack of motivation is a primary characteristic of fatigue (Hockey, 2013) and almost all definitions of cognitive fatigue include some motivational aspect (Kanfer, 2011). Unless cognitive fatigue is extreme, researchers have long considered it to represent a lack of desire, rather than an inability, to engage in a specific action or behavior (Bartley \& Chute, 1947 p. 53). That is, cognitive fatigue is not solely a question of reduced capacity (Webster et al., 1996). The core effect of fatigue is therefore an aversion to (i.e., a lack of motivation for) performing additional activities that demand high levels of cognitive effort (Holding, 1983). This observation aligns with updates to the strength model, which indicate that depletion is an issue of unwillingness, rather than of inability (Baumeister \& Vohs, 2016a p. 81). Indeed, it is the unwillingness to exert additional effort in service of task performance that underlies many of the arguments I make in this section, as motivation mediates the cognitive fatigue-performance relation (Boksem \& Tops, 2008).

To view how motivation influences subsequent performance, it is useful to consider that individuals essentially have three options for goal pursuit. First, assuming individuals place a sufficiently high value on the goal, they can maintain performance levels for a time by increasing effort. Second, if changing the goal is not possible (e.g., in work environments or in experiments through social norms) individuals can continue to pursue the goal with a lower level of effort. Finally, individuals can abandon the current goal and replace it with competing activities that are preferred, though it is not typical for individuals to display a deliberate unwillingness to perform

\footnotetext{
${ }^{8}$ By comparison, Baumeister \& Vohs (2007 pp. 117-118) list four "ingredients" for self-regulation: standards, monitoring, self-regulatory strength (i.e., willpower), and motivation. These authors specifically note that high motivation can compensate for low willpower.
} 
a task (Hockey, 1997). While some depletion researchers implicitly consider only the first and third options (e.g., Baumeister \& Vohs, 2016a), the second option (i.e., continuing a task with lower effort) seems likely to account for the depletion effect. Further, as dependent variable tasks used in prior literature to measure depletion are typically repetitive and/or unpleasant, it is unlikely that individuals regularly have sufficient motivation to increase effort to maintain performance. ${ }^{9}$

OBSERVATION \#2: $\quad$ Updates to the strength model parallel the fatigue literature and a motivationcentric account of depletion as TCF in reflecting that the depletion phenomenon is due to an unwillingness, rather than an inability, to engage in self-regulation.

OBSERVATION \#3: Motivation is a central component of cognitive fatigue and several theories of depletion.

OBSERVATION \#4: Depletion studies typically measure depletion through low-motivation dependent variable tasks; as a result, many observed depletion findings may be due to low motivation rather than an inability to exert effort.

Third, effort regulation is controlled by general and task-specific motivation. Effort can be viewed as "the subjective intensification of mental and/or physical activity in the service of meeting some goal" (Inzlicht et al., 2018 p. 338). While effort is related to motivation, the latter is a distinct concept that refers to a force driving behavior in a specific goal-related direction and the corresponding intensity with which that goal is pursued. Effort provision and regulation involve maintaining information in memory, selecting which information to attend to, avoiding distraction, and suppressing affective responses (e.g., frustration and/or boredom) and the urge to yield to fatigue. Maintaining task goals by engaging in effortful cognitive control is a primary source of fatigue (Hockey, 2013 p. 110; Ackerman, 2011), as fatigue studies find effort is a marker for

\footnotetext{
${ }^{9}$ For example, Vohs et al. (2008), which has garnered nearly 1,300 citations according to Google Scholar, utilizes several examples of unpleasant depletion measures across seven experiments: consuming a beverage comprised of vinegar and water; holding one's arm in freezing cold water; studying instead of playing video games; performing unsolvable puzzles; solving tedious math problems; and spending time watching a broken video before telling the experimenter that it was not working properly. As is apparent, it is unlikely that these tasks engender intrinsic motivation on the part of the participants.
} 
maintaining motivation and/or goal pursuit, and individuals generally avoid effort as a default strategy (Kool et al., 2010; Kurniawan et al., 2011). Further, fatigue leads to a preference for lowereffort strategies, or a reduced motivation for effort exertion following demanding tasks (e.g., Massar et al., 2018; van der Linden, 2011; Hockey \& Earle, 2006).

OBSERVATION \#5: TCF leads to a preference for lower-effort strategies, which can account for findings that depletion reduces task persistence and effortful processing and increases heuristic processing and status quo bias.

Finally, maintaining attention requires continued effort on the focal task and continued maintenance of task goals to avoid task interruption. For example, Kanfer \& Ackerman's (1989) fatigue model indicates that individuals can allocate attention/effort to three areas: on-task, offtask thoughts and distractions (e.g., anxiety, apprehension, other tasks one could engage), and selfregulation. Maintaining task goals requires effortful resistance and cognitive control against competing motivations and attention requirements, and cognitive control mechanisms are especially impacted by fatigue (Bartlett, 1943, 1953; Myers, 1937). Fatigue is therefore associated with difficulty sustaining attention on a specific task for an extended amount of time because maintaining attention and vigilance is cognitively demanding (e.g., Grier et al., 2003; Warm et al., 2008; Smit et al., 2004). For example, cognitive fatigue impedes attention (van der Linden \& Eling, 2006; Boksem et al., 2005), which leads to difficulty focusing on relevant information (Lorist \& Faber, 2011) and engaging in cognition (Lorist, 2008). However, fatigue does not inhibit automatic processing (van der Linden et al., 2003a, 2003b, 2006; Boksem et al., 2005; Lorist \& Faber, 2011) due to its minimal effort requirements (e.g., Dehaene et al., 1998), and can increase procedural (i.e., automatic processing) learning (Borragán et al., 2016).

OBSERVATION \#6: Effortful cognitive control is central to both fatigue and depletion.

OBSERVATION \#7: Neither fatigue nor depletion (e.g., Schmeichel et al., 2003) significantly influences individuals' automatic processing. 


\section{Phases of Cognitive Fatigue}

While there generally exists a positive relationship between time on task and subjective cognitive fatigue (Boksem et al., 2006; Kaneko \& Sakamoto, 2001; Lorist et al., 2000), fatigue is theorized to operate in three distinct phases: transient cognitive fatigue ("TCF"), resistance to fatigue ("RF”), and sustained-effort fatigue (“SEF”) (Hockey, 2013 p. 135). Figure 1 summarizes these three phases. TCF is characterized by low time on task, decreased performance following initial effort exertion, and no long-term after-effects (Hockey, 2013). Individuals may experience TCF only as a vague sense of cognitive discomfort, rather than subjective cognitive fatigue, and Bartlett (1953) argues that feeling tired may represent a late stage in the fatigue process, after fatigue exerts some negative influence on performance. Indeed, Baumeister and Vohs (2016) note that most studies do not reliably find differences in self-reported fatigue; however, this is likely because subjective fatigue is likely to arise after longer effort exertion on a task. Further, fatigue is often measured in post-experimental questionnaires, whereas it is of interest immediately following the manipulation. In this view, TCF can occur and impair performance in just a few minutes of task performance (e.g., Helton et al., 2007; Temple et al., 2000; Balkin \& Wesensten, 2011; Loh et al., 2004) in a manner similar to depletion.

However, some participants may enter the RF phase, which is characterized by accumulating fatigue but a lack of a performance decrement due to increased effort. Therefore, the key difference between participants in the TCF and RF phases is motivation. Specifically, motivated participants will enter the RF phase and maintain performance levels through increased effort provision. By contrast, unmotivated individuals will not enter the RF phase, but will remain in the TCF phase and withhold additional effort, thus exhibiting decreased performance levels. 
This is especially noteworthy when considering the dependent variable tasks employed in previous depletion research and the likelihood that they do not engender motivation among participants.

Figure 1: Summary of Patterns of Fatigue Responses to Tasks (Adapted from Hockey 2013)

\begin{tabular}{llcc}
\multicolumn{1}{c}{ Fatigue Mode } & \multicolumn{1}{c}{ Subjective State } & $\begin{array}{c}\text { Performance } \\
\text { Decrement? }\end{array}$ & $\begin{array}{c}\text { After- } \\
\text { Effects? }\end{array}$ \\
\hline Transient Fatigue (TF) & Minor (transient) fatigue & Yes & No \\
Resistant to Fatigue (RF) & Increasing effort and fatigue & No & Yes \\
Sustained-Effort Fatigue (SEF) & Sustained high effort and fatigue & Yes & Yes \\
\hline
\end{tabular}

OBSERVATION \#8: Depletion studies do not reliably find increased subjective fatigue because in short tasks fatigue may only manifest as a vague sense of cognitive discomfort.

OBSERVATION \#9: TCF can hinder subsequent task performance after a few minutes of initial task performance. This captures the depletion effect, as short bursts of self-control lead to performance impairment. This is especially true if participants are not sufficiently motivated to enter the RF phase and increase effort provision.

By contrast, SEF represents what laypeople most commonly associate with cognitive fatigue. SEF entails feelings of effortful exertion, which lead to a growing feeling of mental tiredness that dampens motivation and/or increases the need to reduce effort or disengage from the task entirely. ${ }^{10}$ This effect is driven by continued effort provision to maintain task goals and performance, prevent task interruptions, and maintain attention on the focal task in the RF phase. Only under extreme conditions would both SEF and impaired performance manifest, when even high levels of effort cannot sustain task performance. Indeed, Ackerman \& Kanfer (2009) provide evidence that subjective fatigue increases with the length of performance on the SAT (e.g., 3.5, 4.5 , or 5.5 hours), yet performance significantly increases with test length. By contrast, field study evidence also indicates that SEF: decreases schoolchildren's exam scores when they start exams later in the day (Sievertsen et al., 2016); reduces hospital workers' compliance with mandatory handwashing later in a 12-hour shift (Dai et al., 2015); leads physicians to overprescribe

\footnotetext{
${ }^{10} \mathrm{SEF}$ can also potentially result from brief task workloads if demands are extreme or intense (Hockey, 2013).
} 
medications more frequently later in the day (Linder et al., 2014); and is associated with abstention or use of shortcuts in voting (Augenblick \& Nicholson, 2016). In an auditing setting, Hurley (2017) finds between-day carryover effects of depletion within (versus outside of) busy season, which is suggestive of SEF as the underlying mechanism.

By contrast, performance is generally expected to decrease with TCF before subjective feelings of fatigue emerge, consistent with the vast majority of depletion research. I contend that these effects are driven by motivational influences on effort provision rather than performance impairments due to the inability to effectively perform the task. It bears repeating that this observation stems from the conclusion that both depletion and TCF result from the unwillingness, rather than the inability to maintain effort and task performance. As a result, participants' performance may suffer on subsequent tasks because they are unwilling to continue to use aversive effortful strategies that require continued cognitive control, rather than the inevitable decline in performance specified by the strength model. Subjective cognitive fatigue leads higher levels of effort to have lower utility (Kanfer, 2011) and results in a shift toward lower-effort strategies (Shingledecker \& Holding, 1974; Schellekens et al., 2000). Importantly, while a break from or significant change in the task can counteract this effect, this is not the case if the new task also demands significant cognitive effort and control (Hockey, 2013), as is typical in depletion studies.

OBSERVATION \#10: SEF is typically not captured in most depletion studies because the tasks are too short. Longer manipulations of depletion do reliably decrease performance (Sjåstad \& Baumeister, 2018; Guilfoyle et al., 2019; Brown \& Bray, 2017; Lopez et al., 2019; Palma et al., 2018; Tsai \& Li, 2019). It is likely that these studies capture TCF-related decreases in performance, coupled with decreased effort provision in lieu of entering the RF phase, which leads to decreased performance.

OBSERVATION\#11: While taking a short break mitigates decreased performance in depletion studies (e.g., Tyler \& Burns, 2008; Friese et al., 2012), switching tasks does not improve performance because the second task also requires significant cognitive effort and control. 


\section{Summary of a Proximate Account of Cognitive Fatigue}

Summing up, I have outlined a proximate account of how fatigue occurs, the mechanisms through which it can influence performance, and how considering depletion to be TCF provides a more accurate depiction of the phenomenon. ${ }^{11}$ As Hockey (2013 p. 142) notes, "fatigue may be thought of as a process that starts as soon as a task begins, taking the form of an increasing bias against current task goals...such effects occur in advance of perceptions of fatigue in terms of sensed effort, though they may be felt vaguely as a state of cognitive discomfort." Thus, fatigue operates by decreasing effort through decreased motivation. If exercising cognitive effort in service of self-control is effortful and individuals' default is to use lower-effort strategies when cognitively fatigued, it stands to reason that they do not fully engage in self-control when not sufficiently motivated to do so. This account is therefore consistent with what is observed in the depletion literature. Overall, it seems that the overlap in findings between the literature attributing effects to ego depletion and those associated with fatigue is more easily accounted for under a view of ego depletion as TCF, which places motivation as the central mechanism.

\section{Reconciling Specific Depletion Findings with Fatigue}

Above I have argued that the ego depletion phenomenon is better explained by considering depletion as TCF. I first present the major findings of the fatigue literature (Hockey, 2013 p. 82) in Figure 2, and note the compatibility of each with depletion. Based upon this analysis, it seems most appropriate to consider mild depletion as TCF and severe depletion as SEF. I next discuss specific findings in the depletion literature and how they map into the fatigue construct.

\footnotetext{
${ }^{11}$ It is also important to discuss fatigue in terms of an "ultimate" (i.e., evolutionary) explanation (Scott-Phillips et al., 2011): why does fatigue occur? Fatigue is adaptive in that it manages our motivational priorities to regulate effort allocation to various goals. The overall purpose of fatigue is to alert individuals to the costs of their current activities and focus them on re-evaluating and/or changing their motivational priorities (Hockey, 2013 p. 104), which contradicts criticism that the motivational account for self-control is not evolutionarily adaptive (Baumeister \& Vohs, $2016 \mathrm{a}$ ).
} 
Figure 2: Comparison of Fatigue and Ego Depletion Findings

Fatigue (Hockey 2013, p. 82)

(1) Decrements [in performance] are not always observed, even in quite long and demanding tasks. Where they were observed, they may be a result of a loss of interest in the work, rather than a genuine impairment of processing effectiveness.

(2) Decrements [in performance] occur more commonly in tasks that are highly repetitive, fast, and continuous.

(3) Decrements [in performance] are generally greater when work is more intense, in terms of workload and effort requirements.

(4) Both rest and a change of task help performance to recover from decrement, though not when the change task makes major demands on executive control.

(5) Following a period of executive control, there is a resistance to continue in a high effort mode.

(6) Under some conditions, decrements [in performance] can be observed very rapidly, within the first minute[s]

(7) Rapid continuous tasks show increasing interruptions in the form of lapses, preceded by increased slowing and errors, and followed by faster, more accurate responding.
Relation to Depletion

Many recent studies both do and do not report a depletion effect (cf. Footnote 6). Further, Milyavskaya et al. (2019b) provide evidence that many of the control conditions in the depletion literature may induce boredom, which can lead to a similar loss of interest in the task as do effortful (i.e., depleting) activities. As a result, many of these null results may be attributable to a lack of a true comparison because boredom and effortful performance may both lead to similar levels of reduced interest on subsequent tasks.

This is a hallmark of many depletion studies, which often assess subsequent performance (i.e., depletion) via variants of the Stroop task (Hagger et al. 2010) or similar interference tasks (e.g., the multi-source interference task in Hagger et al.'s [2016] RRR). Indeed, Dang et al. (2017) find that the Stroop task is one of the most reliable methods of measuring depletion.

This seems true of depletion studies, as studies utilizing longer or more demanding depleting tasks typically report stronger results (e.g., Sjåstad and Baumeister 2018; Guilfoyle et al. 2019; Brown and Bray 2017; Lopez et al. 2019; Palma et al. 2018; Tsai and Li 2019).

This is supported by depletion studies find that rest (e.g., Tyler and Burns 2008; Friese et al. 2012) leads to improved performance (i.e., reduced decrement). The second finding is especially relevant to depletion; depletion studies by definition entail a second task that makes major demands on executive control. This contradicts Baumeister and Vohs's (2016) argument that a motivation explanation of depletion should not lead to decreased performance on a second task.

This is the suggested relationship between initial selfregulation and subsequent impaired self-regulatory performance, which is the basis of the depletion finding.

This is perhaps the hallmark of the depletion effect, as most depletion studies find inhibited subsequent self-regulatory performance after initial exertion lasting less than 10 minutes.

This is difficult to assess in many depletion studies, given the lack of specific testing for this effect. This effect is also potentially confounded with learning effects, making its assessment difficult in the context of depletion. 


\section{Motivation}

While few depletion studies explicitly measure motivation (Baumeister \& Vohs, 2016a), it is clear that motivation plays a significant role in moderating and/or mediating depletion (Baumeister \& Vohs, 2007; Robinson et al., 2010). ${ }^{12}$ Self-control issues are essentially motivational conflicts where efforts to advance long-term/abstract goals directly compete with short-term/concrete goals, and sufficiently motivated individuals will employ all possible strategies to maintain performance in pursuing long-term goals (Fujita, 2011).

Prior depletion studies find that depletion is mitigated when participants are motivated via encouragement or economic incentives (Muraven \& Slessareva, 2003), through self-determination and related motivation (e.g., Legault et al., 2009), when individuals do not expect high demands of future tasks (e.g., Muraven et al., 2006; Katzir et al., 2020), or when the depleting task activates intrinsic motivation through personal relevance of the goal (e.g., Moller et al., 2006; Muraven et al., 2007). Similarly, fatigue research finds that while performance tends to decrease on a continuous task over a long period of performance, rewards (Boksem et al., 2006) and task engagement (Hockey \& Earle, 2006) restore performance levels.

\section{Glucose}

Initial evidence suggested that glucose could be the depleted resource specified by the strength model as responsible for self-regulatory failures (e.g., Gailliot \& Baumeister, 2007; Gailliot et al., 2007). However, reanalysis of the original data (Kurzban, 2010) and accumulating evidence (e.g., Finley et al., 2019; Baumeister \& Vohs, 2016a) strongly contradicts this idea. ${ }^{13}$

\footnotetext{
${ }^{12}$ With respect to a noted lack of findings regarding motivation being a mediator in depletion studies (e.g., Baumeister \& Vohs, 2016a), there are a number of potential explanations. First, most depletion studies do not explicitly or directly measure motivation (Baumeister \& Vohs, 2016a). Second, these motivational shifts are likely to occur subconsciously, as does fatigue, unless they are extreme. Finally, it is possible that there is a demand effect when researchers ask participants how motivated they were in task performance.

${ }^{13}$ This conclusion is consistent with studies finding brain energy is consistent over a wide range of cognitive processes (Raichle \& Mintun, 2006), and with nutrition research (Gibson, 2007; Gibson \& Green, 2002; Rogers \& Lloyd, 1994).
} 
Interestingly, strong support still exists that ingesting (Masicampo \& Baumeister, 2008; McMahon \& Scheel, 2010; Wang \& Dvorak, 2010) or swishing glucose in the mouth (Carter \& McCullough, 2013; Hagger \& Chatzisarantis, 2013; Molden et al., 2012; Sanders et al., 2012) mitigates the depletion effect. Based upon this literature, the Process Model, which I describe in the next section, specifies that glucose still has a role, albeit an unclear one, in observed performance decrements (Inzlicht et al., 2014 p. 128) while Baumeister and Vohs (2016) argue a motivation-centric theory cannot cope with the link between depletion and glucose.

By contrast, I propose that glucose is neurologically linked to motivation by being detected and encoded as rewarding through the anterior cingulate cortex (ACC) and dorso-lateral prefrontal cortex (DLPFC). Indeed, prior studies find that if rewards are not anticipated then ACC activity decreases (Raichle et al., 1994; Shidara \& Richmond, 2002), consistent with the ACC's role in effort regulation. Hagger \& Chatzisarantis (2013) cite evidence that the anterior cingulate cortex (ACC) increases activity in response to tasting glucose. The ACC and DLPFC are both associated with a number of topics in the depletion and fatigue literatures. The ACC is involved in attention allocation (Pardo et al., 1990), reward anticipation and decision-making (Bush et al., 2002), ethics and morality (Sevinc et al., 2017), impulse control (Aharoni et al., 2013), and emotion (Decety \& Jackson, 2004; Jackson et al., 2006). Further, evidence shows that the DLPFC is related to rewards and motivation (Luethi et al. 2016), and decreased DLPFC activity is linked to decreased inhibition (i.e., self-control) (Loftus et al., 2015). The ACC and DLPFC also work in concert to regulate attention shifting and executive control in task goal pursuit (Kondo et al., 2004). The anterior cingulate cortex (ACC) is also ubiquitous in cognitive control, such as processing rewards, performance monitoring, execution of control and action selection (Shenhav et al., 2013). Effort

Thus, while specific local areas in the brain may differ in energy use based upon demands from mental activities, overall glucose levels are maintained within very narrow limits in the brain. 
is tracked by activity in the ACC, which is associated with the subjective aversiveness of effort (Inzlicht et al., 2018 p. 339). As a result, glucose can potentially influence depletion/TCF through increased motivation by being encoded as rewarding by the ACC and DLPFC.

\section{Affect}

Fatigue also shares a substantial overlap with low levels of positive affect (Hockey, 2000), and some researchers refer to fatigue as the "stop emotion" due to its role in interrupting and resetting motivational direction (Meijman, 2000; van der Linden, 2011). This view is compatible with findings in the depletion literature that inducing positive affect or having implicit positive emotion can mitigate depletion (e.g., Mullis \& Hatfield, 2018; Shmueli \& Prochaska, 2012; Ren et al., 2010; Tice et al., 2007) and that enjoying experimental tasks decreases depletion (Polman \& Vohs, 2016; Vohs et al., 2008). The link here is also motivational in nature, as prior literature finds that positive affect fosters intrinsic motivation (Isen \& Reeve, 2005), increases task motivation (Erez \& Isen, 2002), and improves cognitive control through motivation (Liu \& Wang, 2014). Similarly, while Baumeister and Vohs (2016) argue that a motivational account of the depletion phenomenon cannot cope with the association between depletion and negative affect, Gillet et al. (2013) note that amotivation is associated with negative affect, and negative affect may decrease motivation because effort is required to restore one's mood (e.g., Brose et al., 2012).

\section{Self-Affirmation and Self-Efficacy}

Prior studies also find that self-affirmation (Schmeichel \& Vohs, 2009; Wan \& Sternthal, 2008; Alberts et al., 2011) or encouraging individuals to feel autonomous (Graham et al., 2014; Muraven et al., 2007) can counteract depletion. Self-affirmation also increases motivation to achieve goals (e.g., Taylor \& Sherman, 2008), which can account for the increased performance noted in these studies. Baumeister \& Vohs (2016 p. 99) state that findings of self-regulatory 
strength improvement as a result of long-term practice pose a significant threat to a motivationcentric account of depletion findings. However, it is difficult to believe that individuals who practice self-regulation over a long period of time do not experience a heightened sense of selfefficacy in that domain, which can increase goal persistence and goal-striving behavior (Bandura, 1997). As a result, long-term practice studies are consistent with an account of depletion as TCF.

\section{Boredom}

Hockey (2013 p. 16) draws out similarities between boredom and fatigue, noting that boredom can be conceptualized as fatigue absent the motivation and effort required to continue to actively engage with the task and/or its goals. This view of boredom as severely low motivation is compatible with neuroscience evidence from Milyavskaya et al. (2019b), who argue that many control conditions in prior depletion studies may actually induce boredom. Specifically, Milyavskaya et al. (2019b) find that participants in a boredom condition reported significantly greater fatigue and significantly less effort than participants in control or depletion conditions. While O'Hanlon (1981) suggests that boredom is a response to highly repetitious and/or monotonous tasks that are not typical of fatigue-inducing tasks, it is notable that repetitious and monotonous tasks are prototypical of depleting tasks. Thus, boredom provides one potential explanation for the mixed results that characterize the recent depletion literature. Viewing depletion as TCF makes sense of these differences, as participants who are bored and/or exerted significant initial effort will exhibit similar decreases in motivation, effort, and performance.

\section{Construal}

Low-level construal is consistent with focusing on specifics of completing a task, whereas high-level construal is focused on the overall purpose of the task (Trope \& Liberman, 2003, 2010). Self-control is effortful because it pits distal and abstract motivations against proximal and 
concrete motivations, and higher-level construal allows individuals to focus on the former (Fujita, 2011; Fujita et al., 2006). As a result, individuals with lower motivation will likely focus on simply completing the task with lower-level construal, and individuals who find the task meaningful will engage in higher-level construal. Depletion is associated with low-level construal (Bruyneel \& Dewitte, 2012; Wan \& Agrawal, 2011; Vohs \& Schmeichel, 2003), and self-control failure can be viewed as "succumbing to the motivation implied by the low-level [construal]" (Trope \& Liberman, 2010 p. 454). Therefore, it is possible that fatigue reduces motivation, which drives low-level construal and associated reductions in performance observed in depletion studies.

\section{Summary of Specific Depletion Findings and TCF}

In this section, I have summarized numerous specific depletion findings. It seems that an account of depletion as TCF can cleanly accommodate these disparate findings with motivation as the common thread that links these factors to performance outcomes. Motivation is a key component of both TCF and depletion theories. In the next section, I discuss the compatibility of viewing depletion as TCF with existing alternative theories to the strength model of depletion.

\section{Reconciling Competing Depletion Models with TCF}

The preceding discussion makes clear that the depletion literature overlaps considerably with the literature on cognitive fatigue and that reconceptualizing depletion as TCF at a theoretical level can account for the seminal depletion findings as well as the disparate findings and null results that characterize recent depletion research. While the strength model has dominated depletion research, it is important to note that researchers have set forth alternative theories for the depletion phenomenon in response to the overly broad and vague specification of the strength model. I discuss and compare each model below to viewing depletion as TCF. 


\section{The Resource-Allocation Model}

The resource-allocation model ("RAM", Beedie \& Lane, 2012) posits that individuals do not have a limited supply of self-control resources (glucose, in their model), but rather choose whether or not to allocate these resources to specific tasks based upon their underlying motivations. This explanation fits some existing data well, including the conservation hypothesis of depletion (Maranges \& Baumeister, 2017; Tyler \& Burns, 2008; Muraven et al., 2006; Muraven \& Slessareva, 2003). However, it is apparent that part of this model is likely incorrect due accumulating evidence that contradicts the notion that glucose is the limited resource behind selfcontrol. However, at its core the RAM relies upon the concept of motivation in selective allocation of resources. Thus, considering depletion as TCF cleanly subsumes the RAM with one slight change: individuals selectively allocate effort, based upon motivation, rather than a cognitive or physical resource such as glucose. Exerting self-control is effortful, and an abundance of evidence exists that individuals seek to take efficiency shortcuts in cognitive processing.

\section{The Implicit Beliefs Models}

A second alternative theory to the strength model is what I term the Implicit Beliefs Models ("IBMs"). IBM studies find that individuals do not exhibit depletion if they hold certain subjective beliefs, such as believing they have unlimited willpower (Job et al., 2010, 2013; cf. Vohs et al., 2012) or believing they are not depleted or possess optimal resources for task performance (e.g., Clarkson et al., 2010, 2011; Silvestrini et al., 2019). Thus, the IBMs consider depletion to be a self-fulfilling prophecy based upon erroneous beliefs. Importantly, evidence supporting the IBM is also consistent with cognitive dissonance theory (Festinger, 1957), which can be viewed as consistency motivation. Individuals are motivated to create consonance between their actions and beliefs, and this motivation can account for implicit beliefs mitigating the depletion phenomenon, 
consistent with viewing depletion as TCF. Further, personal theories of the self significantly affect motivation (Dweck, 2000) so it stands to reason that personal theories regarding the nature of willpower would function similarly. This view can thus also incorporate the literature on perceived depletion (e.g., Clarkson et al., 2010, 2011; Silvestrini et al., 2019) through parallel logic; individuals who believe they are not depleted would seemingly be motivated to prove that they can maintain task performance to avoid dissonance between the results of their performance and their beliefs. Thus, it is plausible that individuals' beliefs about willpower or perceptions of their own depletion motivate effort provision to enhance performance to be consistent with these beliefs. Thus, considering depletion to be TCF accounts for the findings of the IBMs through motivation.

\section{The Process Model}

The Process Model (“PM”, Inzlicht \& Schmeichel, 2012; Inzlicht et al., 2014) posits that exerting self-control is effortful and therefore concurrently shifts both motivation and attention away from regulating one's behavior and toward more personally gratifying actions. In concert, these processes increase positive affect and emotion, and register as rewarding to the individual. Thus, the PM shares similarities with viewing depletion as TCF, although a fatigue-centric view focuses more broadly on executive functioning while the PM primarily focuses on self-control.

In the PM, effort provision leads to two concurrent consequences: decreased motivation to engage in cognitive control, and increased attention devoted elsewhere (Inzlicht \& Schmeichel, 2012 p. 451). While both effects can and likely do occur, only one task is necessary to observe decreased performance. Based upon the fatigue literature, motivation would be the primary mechanism due to its role in effort provision, as both motivation and effort are superordinate to attention provision and control. The PM also seemingly requires a competing task for an individual to use in assessing comparative motivations, but does not provides an explanation for situations in 
which there is no competing alternative (Hagger 2013). Further, the inclusion of a concurrent/competing task is unnecessary in explaining most depletion findings, and actually runs counter to most experimental designs in this literature. In conclusion, viewing depletion as TCF, while sharing similarities with the PM, has broader explanatory power.

\section{The Opportunity-Cost Model}

The Opportunity Cost Model (“OCM”, Kurzban et al., 2013) argues that exerting effort for self-control highlights the opportunity cost of doing so (i.e., other uses of this effort), which triggers a cost-benefit analysis that can lead to reduced effort and decreased performance observed in the depletion literature. With a focus on motivation for effort and performance and on attention paid to the posited cost-benefit consideration, the OCM has substantial overlap with the PM and viewing depletion as TCF. While Baumeister \& Vohs (2016 p. 105) dismiss the OCM as only relevant for persistence tasks, this argument seems to consider effort as an all-or-nothing proposition, rather than existing on a continuum. Individuals do not typically choose between exerting full effort or quitting a task entirely; rather, they control how much effort to exert in selfregulation based upon their motivation, allowing them to reduce the "cost" of task completion. Similar to viewing depletion as TCF, the OCM identifies the importance of the ACC in continued effort provision, goal pursuit, and persistence (Kurzban et al., 2013). Prior studies have found that heightened ACC activity during decision tasks significantly increases when tasks are that the task is deemed worthy of pursuing (i.e., sufficient motivation exists), but that ACC activity must be sufficiently strong to continue goal pursuit and persistence (Amiez et al., 2005; Hillman \& Bilkey, 2010, 2013; Quilodran et al., 2008; Sallet et al., 2007; Shidara \& Richmond, 2002). However, ACC activity does not always correspond to the costliest action, contrary to the OCM (Hillman \& Bilkey, 2010; Kennerley et al., 2006; Rudebeck et al., 2008). 
Like the PM, the OCM requires a second, competing task as necessary for generating model predictions. In the OCM, this competing task is used to produce an opportunity cost calculation. Like the PM, the OCM does not provide an explanation for situations in which there is no competing alternative task that would trigger an opportunity-cost calculation (Hagger, 2013). It bears repeating that the inclusion of a concurrent/competing task is unnecessary in explaining most depletion findings, and does not mirror most experimental designs in this literature.

Considering depletion as TCF, by contrast, is more parsimonious than the OCM. It is notable that the OCM assumes that individuals objectively conduct cost-benefit calculations, which is at odds with accepted views of human rationality (Inzlicht \& Schmeichel, 2013). Further, the requirement of an alternative task makes little sense when considering that individuals often have no realistic choice between tasks (e.g., feeling obligated to continue an experiment; being unable to realistically quit a task at work). ${ }^{14}$ This choice can be viewed as completing a task with varying degrees of effort on a continuum, with the endpoints being exerting maximal effort or quitting a task altogether. It is far more likely that individuals continue the task out of necessity but reduce their effort due to effort aversion and decreased motivation from cognitive fatigue. This strategy would result in task completion, but at a lower level of performance, consistent with a view of TCF and findings in the depletion literature. ${ }^{15}$

Given that individuals tend to default to lower-effort strategies, it is sufficient for participants to experience reduced motivation in the dependent variable task, lower their effort, and exhibit a decrease in performance as predicted by considering depletion as TCF. For example,

\footnotetext{
${ }^{14}$ While the OCM notes that someone can "daydream" instead of performing their current task, this is essentially using cognitive effort to avoid distraction/task interruption (e.g., Kanfer \& Ackerman, 1989).

${ }^{15}$ Reinforcing this notion, fatigue studies find that individuals typically keep some aspect of performance at acceptable levels while other aspects suffer, rather than being deliberately unwilling to perform a task (e.g., Hockey, 1997). This observation is consistent with reduced task engagement resulting from decreased motivation (van der Linden, 2011), and depletion studies that decreased performance in Stroop accuracy or reaction-time, but not both (Dang et al., 2017 p. 287).
} 
Giacomantonio et al. (2019) provide evidence that depletion leads to two contradictory motivations: 1) to conserve energy; and 2) to seek rewards. Importantly, these motivations can exist concurrently without the need of an alternative competing task. While competing motivations can account for some instances of self-regulatory failure, they are not necessary components of such a model, and fail to account for most of the basic findings in the depletion literature where competing tasks are not prominent.

In summary, considering depletion as TCF can account for the vast majority of the findings of the depletion phenomenon and provides a better fit with and more parsimonious explanation of the findings in the depletion literature than do other alternative depletion theories. This is especially true when considering situations in which individuals do not have strong competing alternative tasks that can draw their motivation from the focal task (e.g., in depletion experiments).

\section{Moving the Literature Forward with Transient Cognitive Fatigue}

\section{Theory Testing}

It seems time to rigorously test an alternative theoretical account of the ego depletion phenomenon (Lurquin \& Miyake, 2017; Friese et al., 2019). By reconceptualizing depletion as TCF, we can derive a number of falsifiable hypotheses. For example, short, effortful tasks will lead to TCF and an associated increase in cognitive discomfort, but not necessarily full self-reports of cognitive fatigue. Absent an increase in motivation from switching to a subsequent task, TCF should also lead to decreased performance on the dependent variable task. Further, if an initial task's effort demands are extreme, participants may report subjective fatigue.

It is also useful to consider predictions in terms of the overall causal process. Tasks resulting in TCF are expected to decrease motivation for continued task performance. This decreased motivation is expected to reduce effort provision while potentially increasing self- 
perceptions of exerted effort. Decreased motivation is also expected to reduce attention to task performance on a subsequent task and increase interference from distractions. That is, an initial task that causes TCF should decrease performance through decreased motivation, but this relationship may potentially be mediated by actual effort provision, reduced attention, and boredom. However, levels of subjective fatigue and how TCF influences performance are unlikely to be fixed between participants; rather, fatigue is a dynamic process that can differ between individuals and tasks and can fluctuate over time (van der Linden, 2011 p. 157). These observations are consistent with those of Baumeister (2019), who posits that depletion may only occur sometimes, but not necessarily all the time. As a result, it is important to consider task duration and obtaining valid measures of potential mediators when examining TCF.

\section{Task Duration}

One open question is: how long or demanding must a task be to shift from TF to RF to SEF? It is difficult to answer such a question, given differences across individuals, tasks' effort demands, and task-individual interaction. However, based upon the fatigue literature, it stands to reason that researchers should observe an initial decrement in task performance through TF with short or moderate-length tasks (e.g., ranging from ten minutes to perhaps an hour), potentially followed by a quasi-rebound effect in the RF phase whereby individuals resist fatigue through effort provision, if they are sufficiently motivated. Following the RF phase is an SEF-driven decline when individuals are unable to sustain performance, again assuming sufficient motivation to continue providing effort. Given prior fatigue literature and laboratory constraints on participants' time, it is perhaps unlikely that SEF will be observed in shorter experiments of less than 30 minutes or one hour. However, researchers can investigate this issue by carefully manipulating time on the initial task to map out performance decrements due to either TCF or SEF. 
For example, some studies examine what could be considered SEF (Linder et al., 2014; Dai et al., 2015; Augenblick \& Nicholson, 2016; Sievertsen et al., 2016; Hurley, 2017) outside of a laboratory. Although this involves some loss of experimental control and introduces potential alternative explanations, such sacrifices are likely necessary to address the different phases of fatigue by leaving the lab (Friese et al., 2019). This seems a fruitful avenue for future research given the broad applicability of both TCF and SEF in work environments.

Researchers must also employ more strongly designed manipulations of TCF compared to many of the depletion manipulations used in prior literature. For example, some recent studies in the depletion literature use manipulations ranging from 24 minutes to two hours (e.g., Sjåstad \& Baumeister, 2018; Guilfoyle et al., 2019; Brown \& Bray, 2017; Lopez et al., 2019; Palma et al., 2018; Tsai \& Li, 2019) and find significant effects on subsequent performance. While some of these studies closer to the two-hour range may arguably be capturing SEF rather than TCF, the important aspect is that these manipulations are generally far stronger than those that are less than ten minutes in duration, typical of the depletion literature (e.g., the Hagger et al., 2016 RRR used a manipulation of $\sim 7.5$ minutes). Using longer and/or more effortfully demanding manipulations will provide some assurance that researchers are effectively manipulating fatigue. Further, researchers should go beyond initial tasks that are centered on self-control to focus on the use of executive functioning to elicit TCF. Finally, another possibility is formally manipulating task motivation. Depletion studies assume that participants are sufficiently engaged in the initial task so as to incur depletion (Lee et al., 2016); however, given the nature of the depleting tasks used in prior studies, this assumption is dubious at best. 


\section{Measures}

While re-specifying ego depletion as TCF provides a more precise theoretical account for the findings in the ego depletion literature, the reader will also note that the process is more complex. This is necessarily the case when moving from a vague resource-based account where effects are simply inferred from performance levels to one that identifies specific causal mechanisms behind a phenomenon. The upshot for continued research in this area is that researchers must obtain a variety of measures to faithfully attempt to conduct falsification tests of the central tenets of depletion as TCF. To date, depletion researchers have given little attention to determining participants' level of exertion during the T1 task beyond self-reported effort and fatigue (Chatzisarantis \& Hagger, 2015; Lee et al., 2016).

First, given the centrality of motivation, effort, and fatigue to TCF, researchers should attempt to measure each of these constructs in a variety of ways. ${ }^{16}$ For example, effort can be measured via self-report in a post-manipulation question, but can also be inferred from time spent on a task, or through other relevant measures determined by experimental design (e.g., number of clicks within an experiment, depth of responses to free-response measures) or physiological markers. Similarly, researchers can assess motivation via direct self-report measures, through indirect self-report measures that focus on interest or types of arousal, through questions that measure goal commitment, or via neuropsychological measures. While fatigue and motivation may often only be measurable by self-report, researchers can also attempt to measure changes in these variables from pre- to post-task, and should encourage subjects to be as honest as possible to avoid experimenter demand effects (e.g., believing it is desirable to report high motivation for the task).

\footnotetext{
${ }^{16}$ Hagger et al. (2010) find support in their meta-analysis for increased subjective perceptions of effort $(d=0.64)$, difficulty $(d=0.94)$, and fatigue $(d=0.44)$ in depletion studies. These findings are consistent with TCF and reinforces the importance of measuring these variables in future studies.
} 
It is also important to obtain measures of participants' mental discomfort, given the observation that TCF may not result in self-report measures of subjective cognitive fatigue. Further, given the link between boredom and motivation, and initial neuroscience evidence that control tasks used in the ego depletion literature may induce boredom among participants (Milyavskaya et al., 2019b), it is important that researchers obtain accurate measures of participants boredom or, conversely, engagement with experimental tasks. It is also important that future research uses various measures to validate tasks used to induce fatigue (cf. Lurquin \& Miyake, 2017). To this end, researchers should validate tasks through the use of multiple measures of the same construct to provide some assurance that the manipulations used are indeed effective. This is of utmost importance, because if participants in manipulated conditions are not sufficiently engaged with or motivated to perform T1 tasks, this may have contributed heavily to the mixed findings and poor understanding of the depletion phenomenon. Further, this will allow researchers to distinguish between individuals who are fatigued, indifferent, or activated by an initial task (Dang \& Hagger, 2019; cf. Converse \& DeShon, 2009; Xiao et al., 2014).

Finally, researchers may need to abandon the dual-task paradigm of ego depletion research (Inzlicht and Schmeichel 2012) and the SEF-driven designs of prior fatigue research to fully explore TCF. The dual-task paradigm is designed with the sole focus of detecting decrements in performance on the T2 task. The preceding discussion of TCF makes it clear that performance should not necessarily be the focal, or certainly not the only, measurement of interest. As a result, it seems that a more fruitful approach may be to isolate various T1 tasks and conduct a battery of post-task questions and tests in order to determine the effects of the T1 task on the individual (e.g., motivation, effort, fatigue, boredom). Such an approach can help to resolve questions of task validity that have plagued depletion studies (Lurquin \& Miyake, 2017) and provide strong 
evidence of the underlying processes that may lead to performance decrements from TCF. This approach can also address the potential usefulness of control tasks, especially considering the possibility that control tasks induce boredom (Milyavskaya et al., 2019b). Given the mediation processes specified in the TFM, this work would provide a crucial building block upon which to test the efficacy of this theoretical re-specification.

\section{Conclusion}

In this paper, I propose that the ego depletion phenomenon is more appropriately viewed as transient cognitive fatigue (TCF). Further, I propose that this reconceptualization of depletion as TCF provides a more appropriate theoretical account of the depletion phenomenon than do the strength model or competing alternative theories of depletion. Rather than abandoning work on this phenomenon, as many researchers have done (e.g., Inzlicht and Friese, 2019 p. 370), it seems more fruitful to re-evaluate the theoretical explanation of the phenomenon and to conduct testing using the theory underlying TCF. This paper thus provides an opportunity for researchers to continue to contribute valuable knowledge about this phenomenon, its generality, and its ability to provide a greater understanding of cognitive fatigue. 


\section{References:}

Ackerman, P.L. (2011). 100 years without resting. In Cognitive Fatigue: Multidisciplinary Perspectives on Current Research and Future Applications, edited by P.L. Ackerman, 11-43. Washington, D.C.: American Psychological Association. https://doi.org/10.1037/12343-001

Ackerman, P.L., \& Kanfer, R. (2009). Test length and cognitive fatigue: An experimental examination of effects on performance and test-taker reactions. Journal of Experimental Psychology: Applied, 15, 163-181. https://doi.org/10.1037/a0015719

Aharoni, E., Vincent, G.M., Harenski, C.L., Calhoun, V.D., Sinnott-Armstrong, W., Gazzaniga, M.S., \& Kiehl, K.A. (2013). Neuroprediction of future rearrest. Proceedings of the National Academy of Sciences, 110 , 6223-6228. https://doi.org/10.1073/pnas.1219302110

Alberts, H.J.E.M., Martijn, C., \& de Vries, N.K. (2011). Fighting self-control failure: Overcoming ego depletion by increasing self-awareness. Journal of Experimental Social Psychology, 47, 58-62. https://doi.org/10.1016/j.jesp.2010.08.004

Amiez, C., Joseph, J.P., \& Procyk, E. (2005). Anterior cingulate error-related activity is modulated by predicted reward. European Journal of Neuroscience, 21, 3447-3452. https://doi.org/10.1111/j.1460-9568.2005.04170.x

Augenblick, N., \& Nicholson, S. (2016). Ballot position, choice fatigue, and voter behaviour. Review of Economic Studies, 83, 460-480. https://doi.org/10.1093/restud/rdv047

Balkin, T.J., \& Wesensten, N.J. (2011). Differentiation of sleepiness and mental fatigue effects. In Cognitive Fatigue: Multidisciplinary Perspectives on Current Research and Future Applications, edited by P.L. Ackerman, 47-66. Washington, D.C.: American Psychological Association. https://doi.org/10.1037/12343-002

Bandura, A. (1997). Self-efficacy: The exercise of control. New York, NY: Freeman.

Bartlett, F.C. (1943). Ferrier lecture: Fatigue following highly skilled work. Proceedings of the Royal Society of London, Series B: Biological Sciences 131: 247-257. https://doi.org/10.1098/rspb.1943.0006

Bartlett, F.C. (1953). Psychological criteria of fatigue. In W.F. Floyd \& A.T. Welford (Eds.) Symposium on Fatigue: 1-5. London, England: H.K. Lewis.

Bartley, S.H., \& Chute, E. (1947). Fatigue and impairment in man. New York: NY: McGraw-Hill.

Baumeister, R.F., Bratslavsky, E., Muraven, M., \& Tice, D.M. (1998). Ego depletion: Is the active self a limited resource? Journal of Personality and Social Psychology, 74, 1252-1265. https://doi.org/10.1037/0022-3514.74.5.1252

Baumeister, R.F. (2002). Ego depletion and self-control failure: An energy model of the self's executive function. Self and Identity, 1, 129-136. https://doi.org/10.1080/152988602317319302

Baumeister, R.F., \& Vohs, K.D. (2007). Self-regulation, ego depletion, and motivation. Social and Personality Psychology Compass, 1, 115-128. https://doi.org/10.1111/j.1751-9004.2007.0$\underline{0001 . x}$

Baumeister, R.F., Vohs, K.D., \& Tice, D.M. (2007). The strength model of self-control. Current Directions in Psychological Science, 16, 351-355. https://doi.org/10.1111/j.1467-8721.2007.00534.X

Baumeister, R.F., \& Vohs, K.D. (2016a). Strength model of self-regulation as limited resource: Assessment, controversies, update. Advances in Experimental Social Psychology, 54, 67-127. https://doi.org/10.1016/bs.aesp.2016.04.001

Baumeister, R.F., \& Vohs, K.D. (2016b). Misguided effort with elusive implications. Perspectives on Psychological Science, 11, 574-575. https://doi.org/10.1177/1745691616652878 
Baumeister, R.F., Tice, D.M., \& Vohs, K.D. (2018). The strength model of self-regulation: Conclusions from the second decade of willpower research. Perspectives on Psychological Science, 13, 141-145. https://doi.org/10.1177/1745691617716946

Baumeister, R. F. (2019). Self-control, ego depletion, and social psychology's replication crisis. In A. Mele (Ed.), Surrounding self-control. New York, NY: Oxford University Press. https://doi.org/10.31234/osf.io/uf3cn

Beedie, C.J., \& Lane, A.M. (2012). The role of glucose in self-control: Another look at the evidence and an alternative conceptualization. Personality and Social Psychology Review, 16, 143-153. https://doi.org/10.1177/1088868311419817

Blázquez, D., Botella, J., \& Suero, M. (2017). The debate on the ego-depletion effect: Evidence from meta-analysis with the $p$-uniform method. Frontiers in Psychology, 8, 197. https://doi.org/10.3389/fpsyg.2017.00197

Boksem, M.A.S., Meijman, T.F., \& Lorist, M.M. (2005). Effects of mental fatigue on attention: An ERP study. Cognitive Brain Research, 25, 107-116. https://doi.org/10.1016/j.cogbrainres.2005.04.011

Boksem, M.A.S., Meijman, T.F., \& Lorist, M.M. (2006). Mental fatigue, motivation, and action monitoring. Biological Psychology, 72, 123-132. https://doi.org/10.1016/j.biopsycho.200$\underline{5.08 .007}$

Boksem, M.A.S., \& Tops, M. (2008). Mental fatigue: Costs and benefits. Brain Research Reviews, 59, 125-139. https://doi.org/10.1016/j.brainresrev.2008.07.001

Borragán, G., Slama, H., Destrebecqz, A. \& Peigneux, P. (2016). Cognitive fatigue facilitates procedural sequence learning. Frontiers in Human Neuroscience, 10, 86. https://doi.org/10.3389/fnhum.2016.00086

Brose, A., Schmiedek, F., Lövdén, M., \& Lindenberger, U. (2012). Daily variability in working memory is coupled with negative affect: The role of attention and motivation. Emotion, 12, 605-617. https://doi.org/10.1037/a0024436

Brown, D.M.Y., \& Bray, S.R. (2017). Graded increases in cognitive control exertion reveal a threshold effect on subsequent physical performance. Sport, Exercise, and Performance Psychology, 6, 355-369. https://doi.org/10.1037/spy0000091

Bruyneel, S.D., \& Dewitte, S. (2012). Engaging in self-regulation results in low-level construals. European Journal of Social Psychology, 42, 763-769. https://doi.org/10.1002/ejsp.1896

Burkley, E. (2008). The role of self-control in resistance to persuasion. Personality and Social Psychology Bulletin, 34, 419-431. https://doi.org/10.1177/0146167207310458

Bush, G., Vogt, B.A., Holmes, J., Dale, A.M., Greve, D., Jenike, M.A., \& Rosen, B.R. (2002). Dorsal anterior cingulate cortex: A role in reward-based decision making. Proceedings of the National Academy of Sciences, 99, 523-528. https://doi.org/10.1073/pnas.012470999

Carter, E.C., \& McCullough, M.E. (2013). After a pair of self-control intensive tasks, sucrose swishing improves subsequent working memory performance. BMC Psychology, 1, 22. https://doi.org/10.1186/2050-7283-1-22

Carter, E.C., \& McCullough, M.E. (2014). Publication bias and the limited strength model of selfcontrol: Has the evidence for ego depletion been overestimated? Frontiers in Psychology, 5, 823. https://doi.org/10.3389/fpsyg.2014.00823

Carter, E.C., Kofler, L.M., Forster, D.E., \& McCullough, M.E. (2015). A series of meta-analytic tests of the depletion effect: Self-control does not seem to rely on a limited resource. Journal of Experimental Psychology: General, 144, 796-815. https://doi.org/10.1037/xge0000083 
Carter, E.C., Schönbrodt, F.D., Gervais, W.M., \& Hilgard, J. (2019). Correcting for bias in psychology: A comparison of meta-analytic methods. Advances in Methods and Practices in Psychological Science, 2, 115-144. https://doi.org/10.1177/2515245919847196

Chatzisarantis, N.L.D., \& Hagger, M.S. (2015). Unsuccessful attempts to replicate effects of selfcontrol operations and glucose on ego-depletion post an interesting research question that demands explanation. Appetite, 84, 328-329. https://doi.org/10.1016/j.appet.2014.10.024

Clarkson, J.J., Hirt, E.R., Jia, L., \& Alexander, M.B. (2010). When perception is more than reality: The effects of perceived versus actual resource depletion on self-regulatory behavior. Journal of Personality and Social Psychology, 98, 29-46. https://doi.org/10.1037/a0017539

Clarkson, J.J., Hirt, E.R., Chapman, D.A., \& Jia, L. (2011). The impact of illusory fatigue on executive control: Do perceptions of depletion impair working memory capacity? Social Psychology and Personality Science, 2, 231-238. https://doi.org/10.1177/1948550610386628

Converse, P.D., \& DeShon, R.P. (2009). A tale of two tasks: Reversing the self-regulatory resource depletion effect. Journal of Applied Psychology, 94, 1318-1324. https://doi.org/10.1037/a0014604

Cunningham, M.R., \& Baumeister, R.F. (2016). How to make nothing out of something: Analyses of the impact of study sampling and statistical interpretation in misleading meta-analytic conclusions. Frontiers in Psychology, 7, 1639. https://doi.org/10.3389/fpsyg.2016.01639

Dai, H., Milkman, K.L., Hofmann, D.A., \& Staats, B.R. (2015). The impact of time at work and time off from work on rule compliance: The case of hand hygiene in healthcare. Journal of Applied Psychology, 100, 846-862. https://doi.org/10.1037/a0038067

Dang, J. (2016). Commentary: "A multilab preregistered replication of the ego-depletion effect." Frontiers in Psychology, 7, 1155. https://doi.org/10.3389//psyg.2016.01155

Dang, J., Björklund, F., \& Bäckström, M. (2017). Self-control depletion impairs goal maintenance: A meta-analysis. Scandinavian Journal of Psychology, 58, 284-293. https://doi.org/10.1111/sjop. 12371

Dang, J. (2018). An updated meta-analysis of the ego depletion effect. Psychological Research, 82, 645-651. https://doi.org/10.1007/s00426-017-0862-x

Dang, J., \& Hagger, M.S. (2019). Time to set a new research agenda for ego depletion and selfcontrol. Social Psychology, 50, 277-281. https://doi.org/10.1027/1864-9335/a000399

Decety, J., \& Jackson, P.L. (2004). The functional architecture of human empathy. Behavioral and Cognitive Neuroscience Reviews, 3, 71-100. https://doi.org/10.1177/1534582304267187

Dehaene, S., Kerszberg, M., \& Changeux, J.P. (1998). A neuronal model of a global workspace in effortful cognitive tasks. Proceedings of the National Academy of Sciences, 95, 14529-14534. https://doi.org/10.1073/pnas.95.24.14529

DeWall, C.N., Twenge, J.M., Koole, S.L., Baumeister, R.F., Marquez, A.. \& Reid, M.W. (2011). Automatic emotion regulation after social exclusion: Tuning to positivity. Emotion, 11, 623636. https://doi.org/10.1037/a0023534

Drummond, A., \& Philipp, M.C. (2017). Commentary: "Misguided effort with elusive implications" and "A multilab preregistered replication of the ego depletion effect." Frontiers in Psychology, 8, 273. https://doi.org/10.3389/fpsyg.2017.00273

Duval, S., \& Tweedie, R. (2000). Trim and fill: A simple funnel-plot-based method of testing and adjusting for publication bias in meta-analysis. Biometrics, 56, 455-463. https://doi.org/10.1111/j.0006-341x.2000.00455.x

Dweck, C.S. (2000). Self-theories: Their role in motivation, personality, and development. Philadelphia, PA: Taylor and Francis. 
Evans, D.R., Boggero, I.A., \& Segerstrom, S.C. (2016). The nature of self-regulatory failure and "ego depletion": Lessons from physical fatigue. Personality and Social Psychology Review, 20, 291-310. https://doi.org/10.1177/1088868315597841

Erez, A., \& Isen, A.M. (2002). The influence of positive affect on the components of expectancy motivation. Journal of Applied Psychology, 87, 1055-1067. https://doi.org/10.1037/00219010.87.6.1055

Festinger, L. (1957). A theory of cognitive dissonance. Stanford University Press.

Finley, A.J., Tang, D., \& Schmeichel, B.J. (2019). Sweet nothings: No effects of self-control exertion on blood glucose levels. Social Psychology, 50, 322-331. https://doi.org/10.1027/1864-9335/a000376

Friese, M., Messner, C., \& Schaffner, Y. (2012). Mindfulness meditation counteracts self-control depletion. Consciousness and Cognition, 21, 1016-1022. https://doi.org/10.1016/j.concog.2012.01.008

Friese, M., Loschelder, D.D., Gieseler, K., Frankenbach, J., \& Inzlicht, M. (2019). Is ego depletion real? An analysis of arguments. Personality and Social Psychology Review, 23, 107-131. https://doi.org/10.1177/1088868318762183

Fujita, K., Trope, Y., Liberman, N., \& Levin-Sagi, M. (2006). Construal levels and self-control. Journal of Personality and Social Psychology, 90, 351-367. https://doi.org/10.1037/00223514.90.3.351

Fujita, K. (2011). On conceptualizing self-control as more than the effortful inhibition of impulses. Personality and Social Psychology Review, 15, 352-366. https://doi.org/10.1177/1088868$\underline{311411165}$

Gailliot, M.T., \& Baumeister, R.F. (2007). The physiology of willpower: Linking blood glucose to self-control. Personality and Social Psychology Review, 11, 303-327. https://doi.org/10.$1177 / 1088868307303030$

Gailliot, M.T., Baumeister, R.F., DeWall, C.N., Maner, J.K., Plant, E.A., Tice, D.M., Brewer, L.E., \& Schmeichel, B.J. (2007). Self-control relies on glucose as a limited energy source: Willpower is more than a metaphor. Journal of Personality and Social Psychology, 92, 325336. https://doi.org/10.1037/0022-3514.92.2.325

Giacomantonio, M., Jordan, J., \& Fennis, B.M. (2019). Intense self-regulatory effort increases need for conservation and reduces attractiveness of energy-requiring rewards. Social Psychology, 50, 355-369. https://doi.org/10.1027/1864-9335/a000395

Gibson, E.L., \& Green, M.W. (2002). Nutritional influences on cognitive function: Mechanisms of susceptibility. Nutrition Research Reviews, 15, 169-206. https://doi.org/10.1079/nrr200131

Gibson, E. (2007). Carbohydrates and mental function: Feeding or impeding the brain? Nutrition Bulletin, 31, 71-83. https://doi.org/10.1111/j.1467-3010.2007.00606.x

Gillet, N., Vallerand, R.J., Lafrenière, M.A.K., \& Bureau, J.S. (2013). The mediating role of positive and negative affect in the situational motivation-performance relationship. Motivation and Emotion, 37, 465-479. https://doi.org/10.1007/s11031-012-9314-5

Graham, J.D., Bray, S.R., \& Ginis, K.A. (2014). "Pay the piper": It helps initially, but motivation takes a toll on self-control. Psychology of Sport and Exercise, 15, 89-96. https://doi.org/10.1016/j.psychsport.2013.09.007

Grier, R.A., Warm, J.S., Dember, W.N., Matthews, G., Galinsky, T.L., Szalma, J.L., \& Parasuraman, R. (2003). The vigilance decrement reflects limitations in effortful attention not mindfulness. Human Factors, 45, 349-359. https://doi.org/10.1518/hfes.45.3.349.27253 
Guilfoyle, J.R., Struthers, C.W., von Monsjou, E., \& Shoikhedbrod, A. (2019). Sorry is the hardest word to say: The role of self-control in apologizing. Basic and Applied Social Psychology, 41, 72-90. https://doi.org/10.1080/01973533.2018.1553715

Hagger, M.S., Wood, C., Stiff, C., \& Chatzisarantis, N.L.D. (2010). Ego depletion and the strength model of self-control: A meta-analysis. Psychological Bulletin, 136, 495-525. https://doi.org/10.1037/a0019486

Hagger, M.S. (2013). The opportunity cost model: Automaticity, individual differences, and selfcontrol resources. Behavior and Brain Sciences, 36, 687-688. https://doi.org/10.1017/s0140525x1300099x

Hagger, M.S., \& Chatzisarantis, N.L.D. (2013). The sweet taste of success: The presence of glucose in the oral cavity moderates the depletion of self-control resources. Personality and Social Psychology Bulletin, 39, 28-42. https://doi.org/10.1177/0146167212459912

Hagger, M.S., \& Chatzisarantis, N.L.D. (2014). It is premature to regard the ego-depletion effect as "too incredible." Frontiers in Psychology, 5, 298. https://doi.org/10.3389/fpsyg.2014.00298

Hagger, M.S., \& Chatzisarantis, N.L.D. (2016). Commentary: "Misguided effort with elusive implications" and "Sifting signal from noise with replication science." Frontiers in Psychology, 7, 1-3. https://doi.org/10.3389/fpsyg.2016.00621

Hagger, M.S., Chatzisarantis, N.L.D., Alberts, H., Anggono, C.O., Batailler, C., Birt, A.R, ... \& Zwienenberg, M. (2016). A multilab preregistered replication of the ego depletion effect. Perspectives on Psychological Science, 11, 546-573.

Helton, W.S., Hollander, T.D., Warm, J.S., Tripp, L.D., Parsons, K.S., Matthews, G., ... \& Hancock, P.A. (2007). The abbreviated vigilance task and cerebral hemodynamics. Journal of Clinical and Experimental Neuropsychology, 29, 545-552. https://doi.org/10.1080/13803390600814757

Hillman, K.L., \& Bilkey, D.K. (2010). Neurons in the rat anterior cingulate cortex dynamically encode cost-benefit in a spatial decision-making task. Journal of Neuroscience, 30, 7705-7713. https://doi.org/10.1523/jneurosci.1273-10.2010

Hillman, K.L., \& Bilkey, D.K. (2013). Persisting through subjective effort: A key role for the anterior cingulate cortex? Behavior and Brain Sciences, 36, 691-692. https://doi.org/10.10$17 / \mathrm{s} 0140525 \times 13001039$

Hockey, G.R.J. (1997). Compensatory control in the regulation of human performance under stress and high workload: A cognitive-energetic framework. Biological Psychology, 45, 73-93. https://doi.org/10.1016/s0301-0511(96)05223-4

Hockey, G.R.J., \& Earle, F. (2006). Control over the scheduling of simulated office work reduces the impact of workload on mental fatigue and task performance. Journal of Experimental Psychology: Applied, 12, 50-65. https://doi.org/10.1037/1076-898x.12.1.50

Hockey, G.R.J. (2011). A motivational control theory of cognitive fatigue. In Cognitive Fatigue: Multidisciplinary Perspectives on Current Research and Future Applications, edited by P.L. Ackerman, 167-187. Washington, D.C.: American Psychological Association. https://doi.org/$10.1037 / 12343-008$

Hockey, G.R.J. (2013). The psychology of fatigue: Work, effort, and control. Cambridge University Press.

Holding, D.H. (1983). Fatigue. In Stress and fatigue in human performance, edited by G.R.J. Hockey. 145-168. Chichester, UK: Wiley.

Hurley, P.J. (2017). Ego depletion and auditors' busy season. Behavioral Research in Accounting, 29, 25-35. https://doi.org/10.2308/bria-51757 
Hurley, P.J. (2021). Making sense of ego depletion: The replication crisis, a path forward, and lessons for accounting researchers. Working paper, Northeastern University.

Inzlicht, M., \& Schmeichel, B.J. (2012). What is ego depletion? Toward a mechanistic revision of the resource model of self-control. Perspectives on Psychological Science, 7, 450-463. https://doi.org/10.1177/1745691612454134

Inzlicht, M., \& Schmeichel, B.J. (2013). Beyond simple utility in predicting self-control fatigue: A proximate alternative to the opportunity cost model. Behavior and Brain Sciences, 36, 695696. https://doi.org/10.1017/s0140525x13001076

Inzlicht, M., Schmeichel, B.J., \& Macrae, C.N. (2014). Why self-control seems (but may not be) limited. Trends in Cognitive Sciences, 18, 127-133. https://doi.org/10.1016/j.tics.2013.12.009

Inzlicht, M., \& Berkman, E. (2015). Six questions for the resource model of control (and some answers). Social and Personality Psychology Compass, 9, 511-524. https://doi.org/10.11$11 / \mathrm{spc} 3.12200$

Inzlicht, M., \& Marcora, S.M. (2016). The central governor model of exercise regulation teaches us precious little about the nature of mental fatigue and self-control failure. Frontiers in Psychology, 7, 656. https://doi.org/10.3389/fpsyg.2016.00656

Inzlicht, M., \& Friese, M. (2019). The past, present, and future of ego depletion. Social Psychology 50, 370-378. https://doi.org/10.1027/1864-9335/a000398

Inzlicht, M., Werner, K.M., Briskin, J.L., \& Roberts, B.W. (2020). Integrating models of selfregulation. Pre-print available from PsyArXiv: https://doi.org/10.31234/osf.io/dpjye

Isen, A.M., \& Reeve, J. (2005). The influence of positive affect on intrinsic and extrinsic motivation: Facilitating enjoyment of play, responsible work behavior, and self-control. Motivation and Emotion, 29, 297-325. https://doi.org/10.1007/s11031-006-9019-8

Jackson, P.L., Brunet, E., Meltzoff, A.N., \& Decety, J. (2006). Empathy examined through the neural mechanisms involving in imagining how I feel versus how you feel pain. Neuropsychologia, 44, 752-761. https://doi.org/10.1016/j.neuropsychologia.2005.07.015

Job, V., Dweck, C.S., \& Walton, G.M. (2010). Ego depletion - is it all in your head? Implicit theories about willpower affect self-regulation. Psychological Science, 21, 1686-1693. https://doi.org/10.1037/e634112013-142

Job, V., Walton, G.M., Bernecker, K., \& Dweck, C.S. (2013). Beliefs about willpower determine the impact of glucose on self-control. Proceedings of the National Academy of Sciences, 110, 14837-14842. https://doi.org/10.1073/pnas.1313475110

Kaneko, K., \& Sakamoto, K. (2001). Spontaneous blinks as a criterion of visual fatigue during prolonged work on visual display terminals. Perceptual and Motor Skills, 92, 234-250. https://doi.org/10.2466/pms.2001.92.1.234

Kanfer, R., \& Ackerman, P.L. (1989). Motivation and cognitive abilities: An integrative/aptitudetreatment interaction approach to skill acquisition. Journal of Applied Psychology, 74, 657690. https://doi.org/10.1037/0021-9010.74.4.657

Kanfer, R. (2011). Determinants and consequences of subjective cognitive fatigue. In Cognitive Fatigue: Multidisciplinary Perspectives on Current Research and Future Applications, edited by P.L. Ackerman, 189-207. Washington, D.C.: American Psychological Association. https://doi.org/10.1037/12343-009

Katzir, M., Emanuel, A., \& Liberman, N. (2020). Cognitive performance is enhanced if one knows when the task will end. Cognition, 197, 104189. https://doi.org/10.1016/j.cognition.2020.104$\underline{189}$ 
Kennerley, S.W., Walton, M.E., Behrens, T.E., Buckley, M.J., \& Rushworth, M.F. (2006). Optimal decision making and the anterior cingulate cortex. Nature Neuroscience, 9, 940-947. https://doi.org/10.1038/nn1724

Kondo, H., Osaka, N., \& Osaka, M. (2004). Cooperation of the anterior cingulate cortex and dorsolateral prefrontal cortex for attention shifting. NeuroImage, 23, 670-679. https://doi.org/10.1016/j.neuroimage.2004.06.014

Kool, W., McGuire, J.T., Rosen, Z.B., \& Botvinick, M.M. (2010). Decision making and the avoidance of cognitive demand. Journal of Experimental Psychology: General, 139, 665-682. https://doi.org/10.1037/a0020198

Kuhn, T.S. (2012). The structure of scientific revolutions. University of Chicago Press.

Kurniawan, I., Guitart-Masip, M., \& Dolan, R. (2011). Dopamine and effort-based decision making. Frontiers in Neuroscience, 5, 81. https://doi.org/10.3389/fnins.2011.00081

Kurzban, R. (2010). Does the brain consume additional glucose during self-control tasks? Evolutionary Psychology, 8, 244-259. https://doi.org/10.1177/147470491000800208

Kurzban, R., Duckworth, A., Kable, J.W., \& Myers, J. (2013). An opportunity cost model of subjective effort and task performance. Behavioral and Brain Sciences, 36, 661-679. https://doi.org/10.1017/s0140525x12003196

Lee, N., Chatzisarantis, N.L.D., \& Hagger, M.S. (2016). Adequacy of the sequential-task paradigm in evoking ego-depletion and how to improve detection of ego-depleting phenomena. Frontiers in Psychology, 7, 136. https://doi.org/10.3389/fpsyg.2016.00136

Legault, L., Green-Demers, I., \& Eadie, A.L. (2009). When internalization leads to automatization: The role of self-determination in automatic stereotype suppression and implicit prejudice regulation. Motivation and Emotion, 33, 10-24. https://doi.org/10.1007/s11031-008-9110-4

Linder, J.A., Doctor, J.N., Friedberg, M.W., Nieva, H.R., Birks, C., Meeker, D., \& Fox, C.R. (2014). Time of day and the decision to prescribe antibiotics. JAMA Internal Medicine, 174, 2029. https://doi.org/10.1001/jamainternmed.2014.5225

Liu, Y., \& Wang, Z. (2014). Positive affect and cognitive control: Approach-motivation intensity influences the balance between cognitive flexibility and stability. Psychological Science, 25, 1116-1123. https://doi.org/10.1177/0956797614525213

Locke, H.S., \& Braver, T.S. (2008). Motivational influences on cognitive control: Behavior, brain activation, and individual differences. Cognitive, Affective, \& Behavioral Neuroscience, 8, 99112. https://doi.org/10.3758/cabn.8.1.99

Loftus, A.M., Yalcin, O., Baughman, F.D., Vanman, E.J., \& Hagger, M.S. (2015). The impact of transcranial direct current stimulation on inhibitory control in young adults. Brain and Behavior, 5, e00332. https://doi.org/10.1002/brb3.332

Loh, S., Lamond, N., Dorrian, J., Roach, G., \& Dawson, D. (2004). The validity of psychomotor vigilance tasks of less than 10-minute duration. Behavior Research Methods, Instruments, \& Computers, 36, 339-346. https://doi.org/10.3758/bf03195580

Lopez, R.B., Courtney, A.L., \& Wagner, D.D. (2019). Recruitment of cognitive control regions during effortful self-control is associated with altered brain activity in control and reward systems in dieters during subsequent exposure to food commercials. PeerJ, 7, e6550. https://doi.org/10.7717/peerj.6550

Lorist, M.M., Klein, M., Nieuwenhuis, S., Jong, R.D., Mulder, G., \& Meijman, T.F. (2000). Mental fatigue and task control: Planning and preparation. Psychophysiology, 37, 614-625. https://doi.org/10.1111/1469-8986.3750614 
Lorist, M.M. (2008). Impact of top-down control during mental fatigue. Brain Research, 1232, 113-123. https://doi.org/10.1016/j.brainres.2008.07.053

Lorist, M.M., \& Faber, L.G. (2011). Consideration of the influence of mental fatigue on controlled and automatic cognitive processes and related neuromodulatory effects. In Cognitive Fatigue: Multidisciplinary Perspectives on Current Research and Future Applications, edited by P.L. Ackerman, 105-126. Washington, D.C.: American Psychological Association. https://doi.org/$10.1037 / 12343-005$

Luethi, M., Friese, M., Binder, J., Boesiger, P., Luechinger, R., \& Rasch, B. (2016). Motivational incentives lead to a strong increase in lateral prefrontal activity after self-control exertion. Social Cognitive and Affective Neuroscience, 11, 1618-1626. https://doi.org/10.1093/scan/nsw073

Lurquin, J.H., \& Miyake, A. (2017). Challenges to ego-depletion research go beyond the replication crisis: A need for tackling the conceptual crisis. Frontiers in Psychology, 8, 568. https://doi.org/10.3389/fpsyg.2017.00568

Maranges, H.M., \& Baumeister, R.F. (2017). The self guides conservation of its regulatory resources. Psychological Inquiry, 28, 108-112. https://doi.org/10.1080/1047840x.2017.$\underline{1337398}$

Marcora, S.M., Staiano, W., \& Manning, V. (2009). Mental fatigue impairs physical performance in humans. Journal of Applied Physiology, 106, 857-864. https://doi.org/10.1152/japplphysiol.91324.2008

Masicampo, E.J., \& Baumeister, R.F. (2008). Toward a physiology of dual-process reasoning and judgment: Lemonade, willpower, and expensive rule-based analysis. Psychological Science, 19, 255-260. https://doi.org/10.1111/j.1467-9280.2008.02077.x

Massar, S.A.A., Csathó, A., \& Van der Linden, D. (2018). Quantifying the motivational effects of cognitive fatigue through effort-based decision making. Frontiers in Psychology, 9, 843. https://doi.org/10.3389/fpsyg.2018.00843

McMahon, A.J., \& Scheel, M.H. (2010). Glucose promotes controlled processing: Matching, maximizing, and root beer. Judgment and Decision Making, 5, 450-457.

Meijman, T.F. (2000). The theory of the stop-emotion: On the functionality of fatigue. In D. Pogorski \& W. Karwowski (Eds.), Ergonomics and safety for global business quality and productivity: 45-50. Warsaw: CIOP.

Milyavskaya, M., Berkman, E.T., \& De Ridder, D.T.D. (2019a). The many faces of self-control: Tacit assumptions and recommendations to deal with them. Motivation Science, 5, 79-85. https://doi.org/10.1037/mot0000108

Milyavskaya, M., Inzlicht, M., Johnson, T., \& Larson, M.J. (2019b). Reward sensitivity following boredom and cognitive effort: A high-powered neuropsychological investigation. Neuropsychologia, 123, 159-168. https://doi.org/10.1016/j.neuropsychologia.2018.03.033

Molden, D.C., Hui, C.M., Scholer, A.A., Meier, B.P., Noreen, E.E., D’Agostino, P.R., \& Martin, V. (2012). Motivation versus metabolic effects of carbohydrates on self-control. Psychological Science, 23, 1137-1144. https://doi.org/10.1177/0956797612439069

Moller, A.C., Deci, E.L., \& Ryan, R.M. (2006). Choice and ego-depletion: The moderating role of autonomy. Personality and Social Psychology Bulletin, 32, 1024-1036. https://doi.org/$10.1177 / 0146167206288008$

Mullis, C.E., \& Hatfield, R.C. (2018). The effect of multitasking on auditors' judgment quality. Contemporary Accounting Research, 35, 314-333. https://doi.org/10.1111/1911-3846.12392 
Muraven, M., Tice, D.M., \& Baumeister, R.F. (1998). Self-control as limited resource: Regulatory depletion patterns. Journal of Personality and Social Psychology, 74, 774-789. https://doi.org $/ 10.1037 / 0022-3514.74 .3 .774$

Muraven, M., \& Slessareva, E. (2003). Mechanisms of self-control failure: Motivation and limited resources. Personality and Social Psychology Bulletin, 29, 894-906. https://doi.org/10.1177/0146167203029007008

Muraven, M., Shmueli, D., \& Burkley, E. (2006). Conserving self-control strength. Journal of Personality and Social Psychology, 91, 524-537. https://doi.org/10.1037/0022-3514.91.3.524

Muraven, M., Rosman, H., \& Gagné, M. (2007). Lack of autonomy and self-control: Performance contingent rewards lead to greater depletion. Motivation and Emotion, 31, 322-330. https://doi.org/10.1007/s11031-007-9073-X

Myers, C.S. (1937). Conceptions of mental fatigue. American Journal of Psychology, 50, 296-306. https://doi.org/10.2307/1416638

Navon, D. (1984). Resources - a theoretical soup stone? Psychological Review, 91, 216-234. https://doi.org/10.1037/0033-295x.91.2.216

Noakes, T.D. (1997). Challenging beliefs: Ex Africa semper aliquid novi. Medicine and Science in Sports and Exercise, 29, 571-590. https://doi.org/10.1097/00005768-199705000-00001

O'Hanlon, J.F. (1981). Boredom: Practical consequences and a theory. Acta Psychologica, 49, 5382. https://doi.org/10.1016/0001-6918(81)90033-0

Palma, M.A., Segovia, M.S., Kassas, B., Ribera, L.A., \& Hall, C.R. (2018). Self-control: Knowledge or perishable resource? Journal of Economic Behavior and Organization, 145, 8094. https://doi.org/10.1016/j.jebo.2017.10.021

Pardo, J.V., Pardo, P.J., Janer, K.W., \& Raichel, M.E. (1990). The anterior cingulate cortex mediates processing selection in the Stroop attention conflict paradigm. Proceedings of the National Academy of Sciences, 87, 256-259. https://doi.org/10.1073/pnas.87.1.256

Pattyn, N., Van Cutsem, J., Dessy, E., \& Mairesse, O. (2018). Bridging exercise science, cognitive psychology, and medical practice: Is "cognitive fatigue" a remake of "The Emperor's New Clothes"? Frontiers in Psychology, 9, 1246. https://doi.org/10.3389/fpsyg.2018.01246

Polman, E., \& Vohs, K.D. (2016). Decision fatigue, choosing for others, and self-construal. Social Psychological and Personality Science, 7, 471-478. https://doi.org/10.1177/19485506166$\underline{39648}$

Powers, W.T. (1973). Behavior: The control of perception. Chicago: Aldine.

Quilodran, R., Rothe, M., \& Procyk, E. (2008). Behavioral shifts and action valuation in the anterior cingulate cortex. Neuron, 57, 314-325. https://doi.org/10.1016/j.neuron.2007.11.031

Raichle, M.E., Fiez, J.A., Vindeen, T.O., MacLeod, A.M., Pardo, J.V., Fox, P.T., \& Petersen, S.E. (1994). Practice-related changes in human brain functional anatomy during nonmotor learning. Cerebral Cortex, 4, 8-26. https://doi.org/10.1093/cercor/4.1.8

Raichle, M.E., \& Mintun, M.A. (2006). Brain work and brain imaging. Annual Reviews of Neurosciences, 29, 449-476. https://doi.org/10.1146/annurev.neuro.29.051605.112819

Ren, J., Hu, L., Zhang, H., \& Zhang, Z. (2010). Implicit positive emotion counteracts ego depletion. Social Behavior and Personality, 38, 919-928. https://doi.org/10.2224/sbp.2010.38 .7 .919

Robinson, M.D., Schmeichel, B.J., \& Inzlicht, M. (2010). A cognitive control perspective of selfcontrol strength and its depletion. Social and Personality Psychology Compass, 4, 189-200. https://doi.org/10.1111/j.1751-9004.2009.00244.x 
Rogers, P.J., \& Lloyd, H.M. (1994). Nutrition and mental performance. Proceedings of the Nutrition Society, 53, 443-456. https://doi.org/10.1079/pns19940049

Rudebeck, P.H., Behrens, T.E., Kennerley, S.W., Baxter, M.G., Buckley, M.J., Walton, M.E., \& Rushworth, F.S. (2008). Frontal cortex subregions play distinct roles in choices between actions and stimuli. The Journal of Neuroscience, 28, 13775-13785. https://doi.org/10.1523/jneurosci.3541-08.2008

Sallet, J., Quilodran, R., Rothe, M., Vezoli, J., Joseph, J.P., \& Procyk, E. (2007). Expectations, gains, and losses in the anterior cingulate cortex. Cognitive Affective Behavioral Neuroscience, 7, 327-336. https://doi.org/10.3758/cabn.7.4.327

Sanders, M.A., Shirk, S.D., Burgin, C.J., \& Martin, L.L. (2012). The gargle effect: Rinsing the mouth with glucose enhances self-control. Psychological Science, 23, 1470-1472. https://doi.org/10.1177/0956797612450034

Sarter, M., Gehring, W.J., \& Kozak, R. (2006). More attention must be paid: The neurobiology of attentional effort. Brain Research Reviews, 51, 145-160. https://doi.org/10.1016/j.brainresrev.2005.11.002

Savani, K., \& Job, V. (2017). Reverse ego-depletion: Acts of self-control can improve subsequent performance in Indian cultural contexts. Journal of Personality and Social Psychology, 113, 589-607. https://doi.org/10.1037/pspi0000099

Schellekens, J.M.H., Sijtsma, G.J., Vegter, E., \& Meijman, T.F. (2000). Immediate and delayed after-effects of long lasting mentally demanding work. Biological Psychology, 53, 37-56. https://doi.org/10.1016/s0301-0511(00)00039-9

Schmeichel, B.J., Vohs, K.D., \& Baumeister, R.F. (2003). Intellectual performance and ego depletion: Role of the self in logical reasoning and other information processing. Journal of Personality and Social Psychology, 85, 33-46. https://doi.org/10.1037/0022-3514.85.1.33

Schmeichel, B.J., \& Vohs, K.D. (2009). Self-affirmation and self-control: Affirming core values counteracts ego depletion. Journal of Personality and Social Psychology, 96, 770-782. https://doi.org/10.1037/a0014635

Scott-Phillips, T.C., Dickins, T.E., \& West, S.A. (2011). Evolutionary theory and the ultimateproximate distinction in the human behavioral sciences. Perspectives on Psychological Science, 6, 38-47. https://doi.org/10.1177/1745691610393528

Sevinc, G., Gurvit, H., \& Spreng, R.N. (2017). Salience network engagement with the detection of morally laden information. Social Cognitive and Affective Neuroscience, 12, 1118- 1127. https://doi.org/10.1093/scan/nsx035

Shenhav, A., Botvinick, M.M., \& Cohen, J.D. (2013). The expected value of control: An integrative theory of anterior cingulate cortex function. Neuron, 79, 217-240. https://doi.org/10.1016/j.neuron.2013.07.007

Shidara, M., \& Richmond, B.J. (2002). Anterior cingulate: Single neuronal signals related to degree of reward expectancy. Science, 296, 1709-1711. https://doi.org/10.1126/science.1069504

Shingledecker, C.A., \& Holding, D.H. (1974). Risk and effort measures of fatigue. Journal of Motor Behavior, 6, 17-25. https://doi.org/10.1080/00222895.1974.10734975

Shmueli, D., \& Prochaska, J.J. (2009). Resisting tempting foods and smoking behavior: Implications from a self-control theory perspective. Health Psychology, 28, 300-306. https://doi.org/10.1037/a0013826 
Sievertsen, H.H., Gino, F., \& Piovesan, M. (2016). Cognitive fatigue influences students' performance on standardized tests. Proceedings of the National Academy of Science, 113, 2621-2624. https://doi.org/10.1073/pnas.1516947113

Silvestrini, N., Vuignier, E., Matthey, A., \& Piguet V. (2019). The perception of available resources influences the after-effect of cognitive control on cognitive performance and pain. Social Psychology, 50, 332-344. https://doi.org/10.1027/1864-9335/a000386

Sjåstad, H., \& Baumeister, R.F. (2018). The future and the will: Planning requires self-control, and ego depletion leads to planning aversion. Journal of Experimental Social Psychology, 76, 127-141. https://doi.org/10.1016/j.jesp.2018.01.005

Smit, A.S., Eling, P.A.T.M., \& Coenen, A.M.L. (2004). Mental effort causes vigilance decrease due to resource depletion. Acta Psychologica, 115, 35-42. https://doi.org/10.1016/j.actpsy.2003.11.001

Sripada, C., Kessler, D., \& Jonides, J. (2014). Methylphenidate blocks effort-induced depletion of regulatory control in healthy volunteers. Psychological Science, 25, 1227-1234. https://doi.org/10.1177/0956797614526415

Sripada, C., Kessler, D., \& Jonides, J. (2016). Sifting signal from noise with replication science. Perspectives on Psychological Science, 11, 576-578. https://doi.org/10.1177/1745691616652875

Stanley, T.D., \& Doucouliagos, H. (2014). Meta-regression approximations to reduce publication selection bias. Research Synthesis Methods, 5, 19-42. https://doi.org/10.1002/jrsm.1095

Stanley, T.D. (2017). Limitations of PET-PEESE and other meta-analytic methods. Social Psychology and Personality Science, 8, 581-591. https://doi.org/10.1177/1948550617693062

Stillman, T.F., Tice, D.M., Fincham, F.D., \& Lambert, N.M. (2009). The psychological presence of family improves self-control. Journal of Social and Clinical Psychology, 28, 498-529. https://doi.org/10.1521/jscp.2009.28.4.498

Taylor, S.E., \& Sherman, D.K. (2008). Self-enhancement and self-affirmation: The consequences of positive self-thoughts for motivation and health. In Handbook of Motivation Science, edited by W. Gardner \& J. Shah, 57-70. New York, NY: Guilford.

Temple, J.G., Warm, J.S., Dember, W.N., Jones, K.S., LaGrange, C.M., \& Matthews, G. (2000). The effects of signal salience and caffeine on performance, workload and stress in an abbreviated vigilance task. Human Factors, 42, 183-194. https://doi.org/10.1518/0018720$\underline{00779656480}$

Thorndike, E.L. (1900). Mental fatigue. Psychological Review, 7, 466-482. https://doi.org/10.$1037 / \mathrm{h} 0069440$

Tice, D.M., Baumeister, R.F., Shmueli, D., \& Muraven, M. (2007). Restoring the self: Positive affect helps improve self-regulation following ego depletion. Journal of Experimental Social Psychology, 43, 379-384. https://doi.org/10.1016/j.jesp.2006.05.007

Trope, Y., \& Liberman, N. (2003). Temporal construal. Psychological Review, 110, 403-421. https://doi.org/10.1037/0033-295x.110.3.403

Trope, Y., \& Liberman, N. (2010). Construal-level theory of psychological distance. Psychological Review, 117, 440-463. https://doi.org/10.1037/a0018963

Tsai, M.-H., \& Li, N.P. (2019). Depletion manipulations decrease openness to dissent via increased anger. British Journal of Psychology, (online access), 1-29. https://doi.org/10.1111/bjop.12387

Tuk, M.A., Zhang, K.J., \& Sweldens, S. (2015). The propagation of self-control: Self-control in one domain simultaneously improves self-control in other domains. Journal of Experimental Psychology: General, 144, 639-654. https://doi.org/10.1037/xge0000065 
Tyler, J.M., \& Burns, K.C. (2008). After depletion: The replenishment of the self's regulatory resources. Self and Identity, 7, 305-321. https://doi.org/10.1080/15298860701799997

Van Cutsem, J., Marcora, S., De Pauw, K., Bailey, S., Meeusen, R., \& Roelands, B. (2017). The effects of mental fatigue on physical performance: A systematic review. Sports Medicine, 47, 1569-1588. https://doi.org/10.1007/s40279-016-0672-0

van der Linden, D., Frese, M., \& Meijman, T.F. (2003a). Mental fatigue and the control of cognitive processes: Effects on perseveration and planning. Acta Psychologia, 113, 45-65. https://doi.org/10.1016/s0001-6918(02)00150-6

van der Linden, D., Frese, M., \& Sonnentag, S. (2003b). The impact of mental fatigue on exploration in a complex computer task: Rigidity and loss of systematic strategies. Human Factors, 45, 483-494. https://doi.org/10.1518/hfes.45.3.483.27256

van der Linden, D., \& Eling, P. (2006). Mental fatigue disturbs local processing more than global processing. Psychological Research, 70, 395-402. https://doi.org/10.1007/s00426-005-0228-7

van der Linden, D., Massar, S.A., Schellekens, A.F.A., Ellenbroek, E.A., \& Verkes, R.J. (2006). Disrupted sensorimotor gating due to mental fatigue: Preliminary evidence. International Journal of Psychophysiology, 62, 168-174. https://doi.org/10.1016/j.ijpsycho.2006.04.001

van der Linden, D. (2011). The urge to stop: The cognitive and biological nature of acute mental fatigue. In Cognitive Fatigue: Multidisciplinary Perspectives on Current Research and Future Applications, edited by P.L. Ackerman, 149-164. Washington, D.C.: American Psychological Association. https://doi.org/10.1037/12343-007

Van Reet, J. (2015). Conflict inhibitory control facilitates pretense quality in young preschoolers. Journal of Cognition and Development, 16, 333-350. https://doi.org/10.1080/15248372.2013.833924

Vohs, K.D., \& Schmeichel, B.J. (2003). Self-regulation and the extended now: Controlling the self alters the subjective experience of time. Journal of Personality and Social Psychology, 85, 217-230. https://doi.org/10.1037/0022-3514.85.2.217

Vohs, K.D., Baumeister, R.F., Schmeichel, B.J., Twenge, J.M., Nelson, N.M., \& Tice, D.M. (2008). Making choices impairs subsequent self-control: A limited-resource account of decision making, self-regulation, and active initiative. Journal of Personality and Social Psychology, 94, 883-898. https://doi.org/10.1037/0022-3514.94.5.883

Vohs, K.D., Glass, B.D., Maddox, W.T., \& Markman, A.B. (2010). Ego depletion is not just fatigue: Evidence from a total sleep deprivation experiment. Social Psychology and Personality Science, 2, 166-173. https://doi.org/10.1177/1948550610386123

Vohs, K.D., Baumeister, R.F., \& Schmeichel, B.J. (2012). Motivation, personal beliefs, and limited resources all contribute to self-control. Journal of Experimental Social Psychology, 48, 943-947. https://doi.org/10.1016/i.jesp.2012.03.002

Vohs, K.D., B.J. Schmeichel, S. Lohmann, Q. Gronau, A.J. Finley, ..., E.-J. Wagenmakers, and D. Albarracín. (in press). A multi-site preregistered paradigmatic test of the ego depletion effect. Psychological Science.

Wan, E.W., \& Sternthal, B. (2008). Regulating the effects of depletion through monitoring. Personality and Social Psychology Bulletin, 34, 32-46. https://doi.org/10.1177/01461672$\underline{07306756}$

Wan, E.W., \& Agrawal, N. (2011). Carryover effects of self-control on decision making: A construal-level perspective. Journal of Consumer Research, 38, 199-214. https://doi.org/$\underline{10.1086 / 658471}$ 
Wang, X.T., \& Dvorak, R.D. (2010). Sweet future: Fluctuating blood glucose levels affect future discounting. Psychological Science, 21, 183-188. https://doi.org/10.1177/0956797609358096

Warm, J.S., Parasuraman, R., \& Matthews, G. (2008). Vigilance requires hard mental work and is stressful. Human Factors, 50, 433-441. https://doi.org/10.1518/001872008x312152

Webster, D.M., Richter, L., \& Kruglanski, A.W. (1996). On leaping to conclusions when feeling tired: Mental fatigue effects on impression primacy. Journal of Experimental Social Psychology, 32, 181-195. https://doi.org/10.1006/jesp.1996.0009

Xiao, S., Dang, J., Mao, L., \& Liljendahl, S. (2014). When more depletion offsets the ego depletion effect. Social Psychology, 45, 421-425. https://doi.org/10.1027/1864-9335/a000197 